\title{
Late Pleistocene glacial-interglacial shell-size-isotope variability in planktonic foraminifera as a function of local hydrography
}

\author{
B. Metcalfe ${ }^{1}$, W. Feldmeijer ${ }^{1}$, M. de Vringer-Picon ${ }^{1}$, G.-J. A. Brummer ${ }^{1,2}$, F. J. C. Peeters ${ }^{1}$, and G. M. Ganssen ${ }^{1}$ \\ ${ }^{1}$ Earth and Climate Cluster, Faculty of Earth and Life Sciences, VU University Amsterdam, \\ De Boelelaan 1085, $1081 \mathrm{HV}$, the Netherlands \\ ${ }^{2}$ Department of Geology and Chemical Oceanography, NIOZ Royal Netherlands Institute for Sea Research, \\ Landsdiep 4, 1797 SZ t' Horntje, Texel, the Netherlands \\ Correspondence to: B. Metcalfe (b.metcalfe@vu.nl)
}

Received: 17 November 2014 - Published in Biogeosciences Discuss.: 6 January 2015

Revised: 30 April 2015 - Accepted: 19 May 2015 - Published: 7 August 2015

\begin{abstract}
So-called "vital effects" are a collective term for a suite of physiologically and metabolically induced variability in oxygen $\left(\delta^{18} \mathrm{O}\right)$ and carbon $\left(\delta^{13} \mathrm{C}\right)$ isotope ratios of planktonic foraminifer shells that hamper precise quantitative reconstruction of past ocean parameters. Correction for potential isotopic offsets from equilibrium or the expected value is paramount, as too is the ability to define a comparable life stage for each species that allows for direct comparison. Past research has focused upon finding a specific size range for individual species in lieu of other identifiable features, thus allowing ocean parameters from a particular constant (i.e. a specific depth or season) to be reconstructed. Single-shell isotope analysis of fossil shells from a mid-latitude North Atlantic Ocean piston core covering Termination III (200 to $250 \mathrm{ka}$ ) highlight the advantage of using a dynamic size range, i.e. utilising measurements from multiple narrow sieve size fractions spanning a large range of total body sizes, in studies of palaeoclimate. Using this methodology, we show that isotopic offsets between specimens in successive size fractions of Globorotalia inflata and Globorotalia truncatulinoides are not constant over time, contrary to previous findings. For $\delta^{18} \mathrm{O}$ in smaller-sized globorotalids $(212-250 \mu \mathrm{m})$ it is suggested that the offset from other size fractions may reflect a shallower habitat in an early ontogenetic stage. A reduction in the difference between small and large specimens of $G$. inflata between insolation minima and maxima is interpreted to relate to a prolonged period of reduced water column stratification. For the shallow-dwelling species Globigerina bulloides, no size-isotope difference between size fractions is observed, and the variability in the oxygen iso-
\end{abstract}

topic values is shown to correlate well with the seasonal insolation patterns. As such, patterns in oxygen isotope variability of fossil populations may be used to reconstruct past seasonality changes.

\section{Introduction}

\subsection{Size of planktonic foraminifera}

A series of biogeochemical and physical proxies determine the mechanisms of short-term and long-term climate change from archives such as deep sea sediments. Notably amongst these is the oxygen and carbon isotope composition of planktonic foraminifera because of the continuous export flux of shells to the ocean floor and their near-global occurrence. The inherent weakness within these proxy archives is that these are neither the original nor the unaltered reflection of the primary signal. Therefore, quantifying the limitations and potential artefacts is imperative for drawing robust conclusions. Vital effects are isotopic offsets from equilibrium values reflecting biological fractionation, i.e. changes in metabolic processes and growth rates during shell formation. The isotopic composition has been shown to be a function of the ambient carbonate ion concentration $\left(\left[\mathrm{CO}_{3}^{2-}\right]\right.$; e.g. Spero et al., 1997), temperature (e.g. Bemis et al., 2000) and post-mortem effects (e.g. Lohmann, 1995; Rosenthal et al., 2000). Previous studies have shown that, in order to minimise or reduce the potential influence of metabolic effects and therefore spurious palaeoenvironmental reconstructions, 
specimens should be constrained to a similar size and shape (Berger et al., 1978a, b; Billups and Spero, 1995; BouvierSoumagnac and Duplessy, 1985; Curry and Matthews, 1981; Elderfield et al., 2002; Friedrich et al., 2012; Kroon and Darling, 1995; Ravelo and Fairbanks, 1992, 1995; Shackleton and Vincent, 1978; Weiner, 1975; Williams et al., 1981). Shell size dependence of isotopic offsets from dissolved carbonates (e.g. Kahn, 1979; Curry and Mathews 1981; Kahn and Williams, 1981; Oppo and Fairbanks, 1989; Elderfield et al., 2002; Hillaire-Marcel et al., 2004) also serves to further complicate matters. However, the factors that govern/regulate the biomineralisation process in planktonic foraminifera are currently not implicitly understood, with many studies making no distinction between biocalcification and inorganic precipitation. Weinkauf et al. (2013) considered that there is some implied trade-off, with respect to resource allocation, between production of biomass and biomineralisation; this would fit with the implicit assumption of the optimum growth hypothesis of de Villiers (2004), which is consistent with size reflecting optimum ecological conditions (Schmidt et al., 2004). Shell size, in itself, reflects an easily measured parameter with a direct relation between both inherited (genetic) and environmental stimuli (e.g. temperature, availability of food). In practical terms, throughout its life an organism will invariably increase in size until some discrete threshold limit is reached due to either mechanical (i.e. test construction), physiological (i.e. maturation; reproduction) or physical constraints (i.e. abiotic/biotic factors) (Schmidt et al., 2004, 2006, 2008). Schmidt et al. (2006) considered that optimum conditions for planktonic organisms could either lead to rapid reproduction and therefore small body size, or fast growth rates and hence larger sizes. Hecht et al. (1976) demonstrated the latter using North Atlantic core-top material, i.e. that species of planktonic foraminifera obtain their maximum size in waters that are considered (close to) optimal for that species, decreasing in size away from this point. However, what is considered optimal for pelagic organisms can be complicated by the fact that optimal conditions can occur both geographically and vertically (water depth) (Telford and Kucera, 2013). Despite this, as environmental conditions change through time, organisms can either adapt to new conditions (i.e plasticity: ecophenotypes) or "track" their preferred habitat, leading to a change in body size, the severity of which is dependent upon the location (Malmgren and Kennett, 1976). Whilst foraminifera are limited in their ability to track their preferred habitat, being freefloating members of the plankton, it is likely when transported into favourable environmental conditions that growth occurs (van Sebille et al., 2015). The effect of this plasticity of size, and potential growth rate variations, upon stable isotopes is less clear.

Emiliani (1954) was the first to investigate the isotopic composition of foraminifera of two different sizes (250-500 and $500-1000 \mu \mathrm{m})$. A subsequent study extending this line of enquiry (Emiliani, 1971) postulated that this size-isotope relationship could be influenced by a change in depth habitat after finding a difference between samples from glacials and interglacials. Certainly, if depth habitats are ultimately constrained by food supply and therefore by the penetrative depth of light, then during glacials, when productivity was high, a reduced transmission of light may have occurred (Volten et al., 1998), and thus foraminifera would have undergone an "upward migration" of depth habitats (Berger et al., 1978). Whilst a depth-habitat ranking based upon large specimens would not differ from the general attribution of depth to individual species, this is not the case for smallersized groups, which in general have a warmer and thus shallower signal (Kahn, 1978). Subsequent investigations have contented themselves with using a single depth in core, or core top, to determine the size-isotope relationship at a given geographic location despite these earlier postulations to the contrary.

\subsection{Aims and objectives}

Here we test the sensitivity of planktonic foraminiferal shell size to a large-scale environmental perturbation across a glacial-interglacial transition by focusing upon Termination III (TIII). The transition from Marine Isotope Stage (MIS) 8 to 7 at around $232 \mathrm{kyr} \mathrm{BP}$ (T III), studied here, is generally characterised by a reduced amplitude in oxygen isotope values compared with other glacial terminations, as the preceding cold stage (MIS 8) is muted, with only a reported shift of $\sim 1.1 \%$ in benthic foraminiferal $\delta^{18} \mathrm{O}$. MIS 7 is composed of three warm (MIS 7 substages MIS 7a, 7c and 7e) and two cold phases (MIS 7 substages MIS 7b and 7d) (Roucoux et al., 2006) with the termination characterised by relatively high eccentricity and hence by a heightened difference in the maximum seasonal insolation as defined by the difference between the maximum and minimum insolation during the year (Berger et al., 2006). We utilise data from Feldmeijer et al. (2015) and present new data that expands upon shellsize-isotope relationships between species and through time (Birch et al., 2013; Friedrich et al., 2012) through the use of single-shell stable isotope analysis (Ganssen et al., 2011, and references therein). Individual foraminifera were picked from narrow size fractions (212-250, 250-300, 300-355 and $355-400 \mu \mathrm{m})$ from a section of JGOFS APNAP core T909p ( $45^{\circ} 17.5^{\prime} \mathrm{N}, 27^{\circ} 41.3^{\prime} \mathrm{W}$; core length: $1028 \mathrm{~cm}$; Fig. 1), recovered from the eastern flank of the Mid-Atlantic Ridge (water depth $2934 \mathrm{~m}$ ), in the North Atlantic Ocean (Lototskaya and Ganssen, 1999; Lototskaya et al., 1998; Feldmeijer et al., 2015). Sedimentation rate in the core interval selected is between 1.7 and $3.1 \mathrm{~cm} \mathrm{kyr}^{-1}$, dissolution is considered to be minimal (Feldmeijer et al., 2015). Data on small $(212-250 \mu \mathrm{m})$ and large $(355-400 \mu \mathrm{m})$ specimens of both dextrally and sinistrally coiled Globorotalia truncatulinoides are reported elsewhere (Feldmeijer et al., 2015). Planktonic foraminifera collected from sediments form the basis of palaeoceanographic reconstructions, usually through 


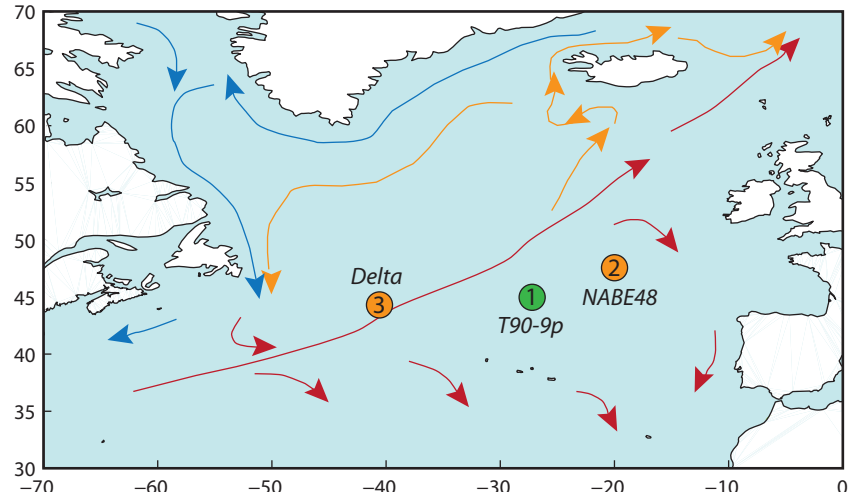

Figure 1. Location map of the North Atlantic region. Location map of (1) piston core APNAP T90-9p and long-term observation stations, (2) sediment trap NABE 48 (Wolfteich, 1994) and (3) Ocean Station Delta (Bé and Tolderlund, 1971) with main surface ocean currents overlain. Colour indicates relative temperature of the dominant water mass, with red to blue representing warmest to coolest.

$\delta^{18} \mathrm{O}$ and $\delta^{13} \mathrm{C}$ on multiple specimens. If multi-specimen analyses were repeated several times, then the variability would be expected to be smaller compared with the variability one would obtain if specimens were measured individually. This variability is expected to decrease with the reciprocal value of the square root of the number of specimens within a single analysis. In other words by combining multiple specimens for each analysis the variability is reduced for the sake of eliminating noise that may otherwise unduly influence time series analysis. The isotopic information within single specimens is, however, lost. Given the dynamic nature of the ocean, individuals collected together in a single sedimentary sample may have calcified in different seasons (or years), at different depths, or even in different water masses. Intra- and inter-specific variability in isotopes have been used to explain either upper ocean processes such as (1) calcification depth changes (Emiliani, 1954), (2) variations in metabolism through ontogeny (Killingley et al., 1981; Vergnaud-Grazzini, 1976; Rink et al., 1998) and/or bottom water processes, (3) bioturbation and benthic organism interaction (Bard, 2001; Bard et al., 1987; Löwemark et al., 2008; Wit et al., 2013) and (4) dissolution/recrystallisation (Bonneau et al., 1980). Given that the life cycle of upper oceandwelling species is probably completed within a few weeks (Bé et al., 1977; Berger, 1969), and that a single chamber is formed over a few hours, single-shell analysis allows us to notice short-term conditions in the ocean (Killingley et al., 1981).

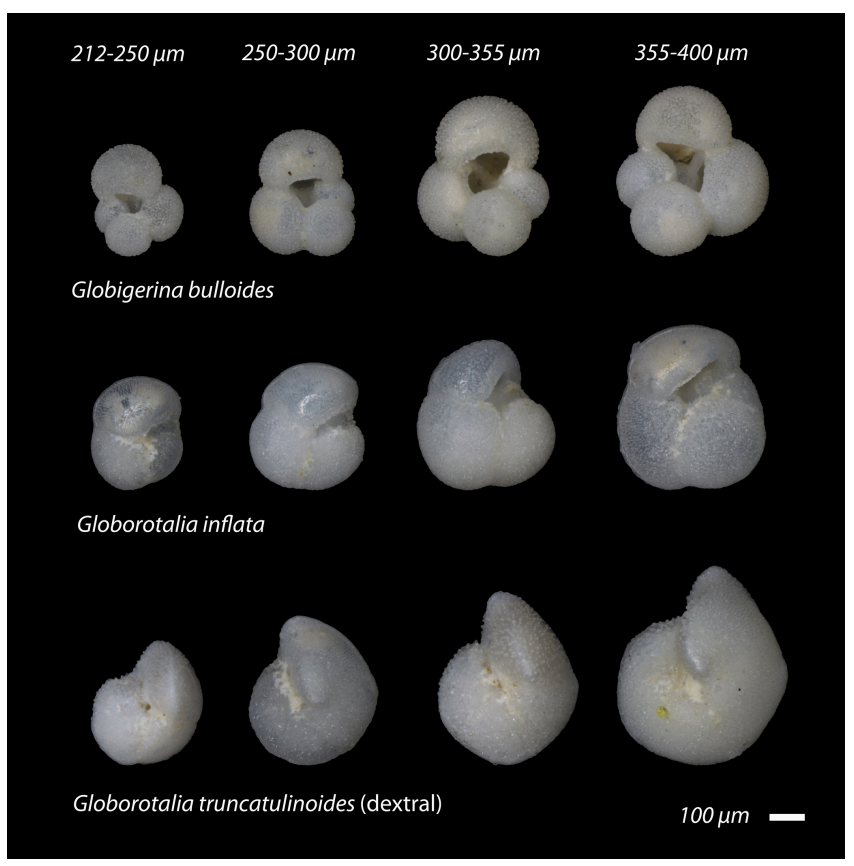

Figure 2. Taxonomy and size of species analysed in this paper. Apertural view of the "surface dweller" Globigerina bulloides (top row), "intermediate dweller" Globorotalia inflata (middle row) and the "deep dweller" Globorotalia truncatulinoides (bottom row)for the size fractions $212-250,250-300,300-355$ and $355-400 \mu \mathrm{m}$ from a $756 \mathrm{~cm}$ depth core. Scale bar $(100 \mu \mathrm{m})$ is the same for all images, highlighting the offset between the various size fractions.

\section{Methodology}

\subsection{Calculation of average size and faunal abundance}

Abundance counts of planktonic foraminifera were performed at $4 \mathrm{~cm}$ resolution on sediment that was first weighed so that the proportion of $<63 \mu \mathrm{m}$ could be computed, then washed over a sieve with a $63 \mu \mathrm{m}$ mesh and dried overnight in an oven at $50^{\circ} \mathrm{C}$. Once dry it was passed over a nest of sieves with mesh sizes of 125, 212, 250, 300, 355 and $400 \mu \mathrm{m}$. Each size fraction was weighed and split using an OTTO microsplitter into small aliquots approximately containing two hundred particles and the number of Globigerina bulloides, Globorotalia inflata and Globorotalia truncatulinoides (Fig. 2) counted for each size fraction. Counts were subsequently converted into numbers per gram by multiplying the absolute number of individuals by the split, and the size frequency distribution (SFD) was approximated, following the methodology of Peeters et al. (1999).

\subsection{Stable isotope geochemistry $\left(\delta^{18} \mathrm{O}\right)$}

Measurements using multiple specimens routinely consist of between 8 and 40 individuals, which, depending on the species, represent $\sim 0.30-1.50 \mathrm{mg}$ of calcium carbonate per sample (Waelbroeck et al., 2005a). Sample preparation in 
combination with improved mass spectrometry techniques now allows for measurement of single shells down to a few micrograms (Ganssen et al., 2011), or even analysis to the level of individual chambers (Kozdon et al., 2009; Vetter et al., 2013) depending on the analytical methodology followed. This constitutes an improvement by a factor of 10 1000 compared to the early pioneering studies of Emiliani (1955) and Shackleton (1965). Specimens of G. bulloides, $G$. inflata and $G$. truncatulinoides were analysed singularly with up to 20 individuals picked from each of four successive size fractions $(212-250,250-300,300-355$ and 355$400 \mu \mathrm{m})$ following ultrasonic cleaning in ethanol. Analysis was conducted on a Thermo Finnigan Delta ${ }^{+}$mass spectrometer equipped with a GasBench II preparation device. In order to analyse individual specimens, ranging in weight between 5 and $50 \mu \mathrm{g}$, samples are placed in He-filled $3 \mathrm{~mL} \mathrm{Ex-}$ etainer vial with a set of glass beads $(\sim 2 \mathrm{~mm})$. The beads act both as a heat buffer and as a preventative measure against loss upon on contact with the acid, a problem that is generally overcome when measuring in groups. Each sample is digested in concentrated phosphoric acid $\left(\mathrm{H}_{3} \mathrm{PO}_{4}\right)$ at $45^{\circ} \mathrm{C}$. Isotope values are reported as $\delta^{18} \mathrm{O}$ and $\delta^{13} \mathrm{C}$ versus Vienna Pee Dee Belemnite (V-PDB) calculated using the standard delta notation $(\delta)$ and reported in per mil $(\% o)$. The reproducibility of routinely analysed laboratory calcium carbonate standards is better than $0.12 \% o(1 \sigma)$ for both $\delta^{18} \mathrm{O}$ and $\delta^{13} \mathrm{C}$, given the heterogeneity of carbonate standards at this critical low concentration of material analysed (Ishimura et al., 2008). This represents $\sim 5 \%$ of the measured range and is therefore considered negligible.

\subsection{Statistical analysis}

Single-specimen analysis allows for a more stringent battery of statistical tests to be carried out than "traditional", grouped analysis. We follow methodological procedures described in Ganssen et al. (2011), in which the individual data sets (multiple analyses of single specimens from one size fraction) are checked for potential outliers in order to produce a robust estimate of both the range and the mean. The lower and upper bound were calculated using the first quartile $\left(Q_{1}\right)$, third quartile $\left(Q_{3}\right)$ and the interquartile range (IQR). Outlier detection and removal via IQR removes, by its very definition, the extremes in $\delta^{18} \mathrm{O}_{\mathrm{c}}$ and, therefore, potentially the minimum and maximum temperatures. However, comparison of size fractions using a Student $t$-distribution-based confidence interval necessitates a robust mean, free from influence of extremes. Whilst no data set fits the normal distribution, distributions that approximate the normal distribution are considered to be unimodal with the measures of central tendency (mean, median and mode) equal and located at the centre of the curve. Only a few depths in core showed significant evidence to reject normality, based upon a Shapiro-Wilk test; however for convenience and for a visual comparison we assumed that they were normal when generating a $t$-based con- fidence intervals on the mean. For all figures we present the means with the attached $95 \%$ confidence level; given that our experimental design is an attempt to discern whether the size fractions, and thus for simplicity their means, are statistically similar or different, this confidence level was chosen so as to not mislead the reader as they encompass a larger uncertainty.

Two $t$ tests were performed, the first to test for any statistical difference between all four size fractions with each species in each sample and the second to test whether the differences between size fraction isotope values are constant within each species downcore; these were performed as follows: (1) in order to examine whether there is a significant relationship between size and stable isotopes, a one-sample $t$ test was performed on the differences, smallest size fraction value minus the largest, between the means of the size fractions of both $\delta^{18} \mathrm{O}$ (Table 1) and $\delta^{13} \mathrm{C}$ (Table 3). This statistical choice is the result of speed and efficiency, as it would require six paired $t$ tests per sample multiplied by 26 samples, increasing the likelihood of an error associated with a false positive. The null hypothesis of the performed test is that the difference in $\delta^{18} \mathrm{O}$ and $\delta^{13} \mathrm{C}$ between two size fractions is zero $\left(H_{0}: \mu_{1}-\mu_{2}=0\right)$; thus all means are equal $\left(H_{0}: \mu_{1}=\mu_{2}=\mu_{3}=\mu_{4}\right)$, and the resultant hypothesis is that at least one of the means is different from the others $\left(H_{1}\right.$ : $\mu_{1} \neq \mu_{2} \neq \mu_{3} \neq \mu_{4}$ ). Analysis was performed at both the 90 and $95 \%$ confidence level ( $\alpha$ values of 0.10 and 0.05 ; critical $t$ values of 2.015 and 2.571, respectively). For (2) testing whether the relationship remains constant through time over a large climatic perturbation, a two-tailed $t$ test for dependent samples was performed between size fractions for the entire core $(n=6)$. The $H_{0}$ is that the differences between size fractions are zero, and thus all means equal, and that this is consistent down-core. The critical values of the $t$ distribution for $n=26$ samples of the 90 and $95 \%$ confidence level ( $\alpha$ values of 0.10 and 0.05 ) are 1.708 and 2.060, respectively. No ice volume correction prior to statistical analysis was performed as it was deemed that the difference between two size fractions within the same sample should negate this effect.

The downcore means of the smallest $(212-250 \mu \mathrm{m})$ and largest $(355-400 \mu \mathrm{m})$ specimens of all species were plotted against each other for both $\delta^{18} \mathrm{O}$ and $\delta^{13} \mathrm{C}$, respectively, as per Sarkar et al. (1990) (Table 2). The resultant slope was tested against a $1: 1$ relationship or iso- $\delta$ line using a twotailed $t$ test; the slope of such a line is considered to be unity as $y$ would be equal to $x\left(H_{0}\right.$ : slope $=1 ; H_{1}$ : slope $\left.\neq 1\right)$. Deviations from the iso- $\delta$ line would indicate a change in the relative depletion or enrichment between the two size fractions at either the warm or cold temperature end for $\delta^{18} \mathrm{O}$. To calculate the estimated standard error of the regression, the vertical difference between the observed and fitted values, using a linear regression, was calculated using ordinary least squares (OLS), which minimises the resultant sum of the squared residuals (SSR). The magnitude of the SSR is influenced by the number of data points; a larger number of 


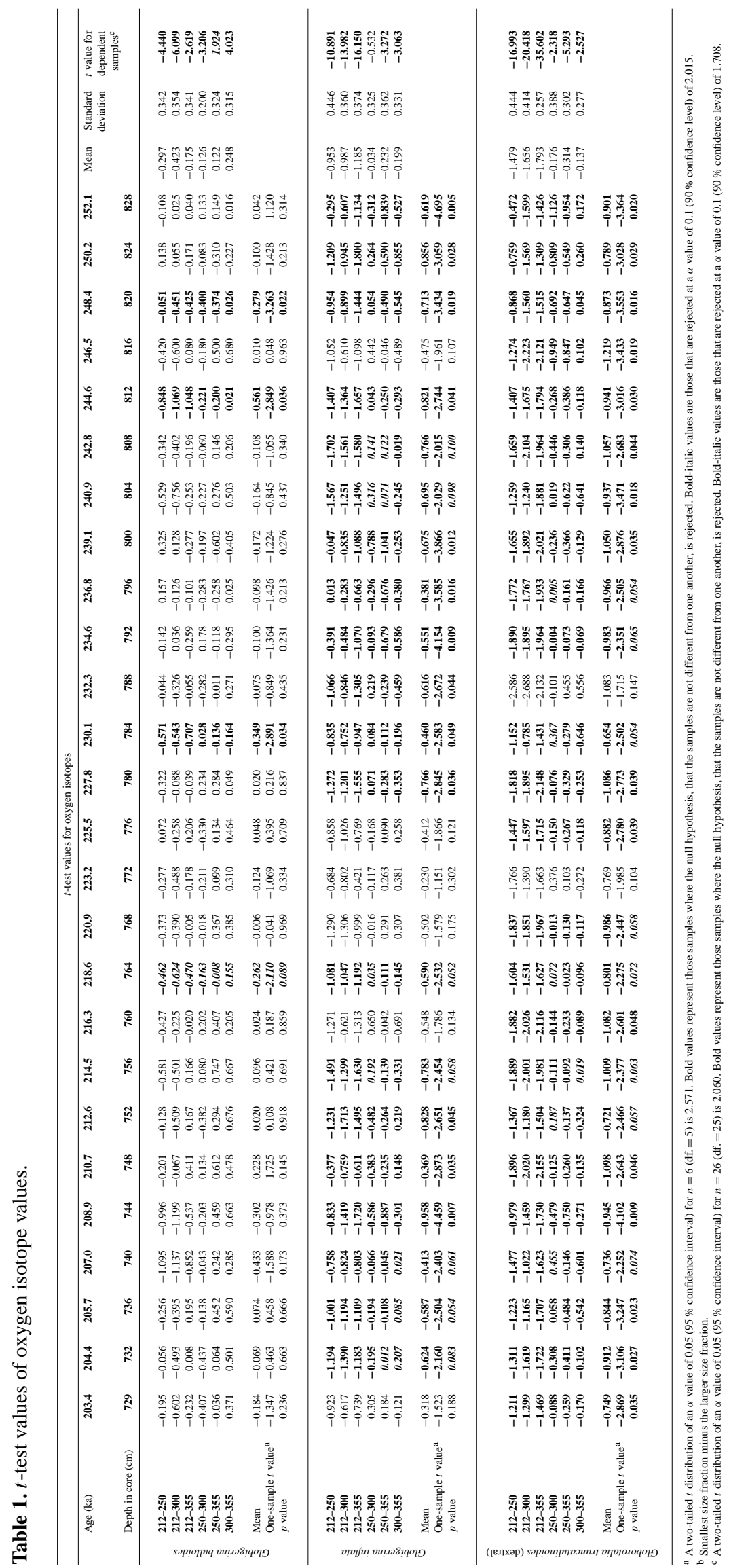


Table 2. Smallest and largest size fraction linear regression and $t$-test values.

\begin{tabular}{lcc|c|c|c}
\hline \multicolumn{2}{c}{ Test values for smallest-largest cross-plot } & & & \\
\hline Species & \multicolumn{2}{c|}{$y=a x+b$} & $r^{2}$ & $t$ test value for $r^{2}$ a & $t$ value \\
& $a$ & $b$ & & & \\
\hline Oxygen isotope values & & & & & \\
G. bulloides & 0.8033 & 0.4535 & 0.6432 & 6.5776 & -1.305 \\
G. inflata & 0.5687 & 1.5919 & 0.3433 & 3.5421 & -1.288 \\
G. truncatulinoides & 0.8929 & 1.8467 & 0.6626 & 6.853 & -1.669 \\
\hline Carbon isotope values & & & & & \\
G. bulloides & 0.2345 & -0.324 & 0.1315 & 1.9063 & -2.319 \\
G. inflata & 0.1277 & 0.6448 & 0.1107 & 1.7284 & -3.393 \\
G. truncatulinoides & 0.2231 & 0.7924 & 0.0775 & 1.42 & -2.887 \\
\hline
\end{tabular}

${ }^{\mathrm{a}} H_{0}: p=0, H_{1}: p \neq 0$. Two-tailed $t$ test value for $\alpha 0.05$ is $2.064 ;{ }^{\mathrm{b}} H_{0}:$ slope $=1, H_{1}: p \neq 1$. Two-tailed $t$-test value for $\alpha 0.05$ is 2.064 .

data points results in a larger SSR. To account for this, it was divided by the degrees of freedom $(n-2)$. The resultant expression was square-rooted. The test value at $\alpha 0.05$ for a two-tailed test is 2.064 for $n=26$.

Interdependence, or the degree of linear relationship, between $\delta^{18} \mathrm{O}$ and $\delta^{13} \mathrm{C}$ was tested for using covariance upon the outlier corrected values of oxygen and carbon for each size fraction and for all size fractions combined (Table 4 and 5) using the PAST software package (Hammer et al., 2001). Independence, where $\delta^{18} \mathrm{O}$ and $\delta^{13} \mathrm{C}$ vary without a connection, is implied when covariance has a value of 0 , or the relationship between the two parameters is nonlinear. The degree to which values larger than 0 are independent necessitates transformation into a dimensionless quantity independent of scaling relationships. Therefore we interpret the data using the correlation coefficient, in which the covariance is divided by the product of the standard deviation of both oxygen and carbon. Such transformation gives a limit of \pm 1 , in which values that approach \pm 1 represent a higher degree of linear codependence.

\section{Results}

\subsection{Faunal abundance counts and size}

Over the time period of interest, G. truncatulinoides abundance is generally $<10 \%$ (Fig. 3). Faunal abundance for $G$. inflata ranges between 10 and $40 \%$, with higher abundance corresponding with warmer intervals in MIS7 and the lower abundances preceding the cold interval in MIS8. The abundance for $G$. bulloides ranges between 10 and $35 \%$, appearing to follow the expansion and contraction of insolation, with periods of reduced seasonality, i.e. milder (lower insolation) summer and winter months, showing higher relative abundances (Fig. 3). Calculated average size for this interval falls between 250 and $300 \mu \mathrm{m}$ for both $G$. bulloides and $G$. inflata, with only minor variation $(\sim 30 \mu \mathrm{m})$ (Fig. 3c). The size of G. truncatulinoides is more erratic varying between 250 and $355 \mu \mathrm{m}$, especially between 227 and $252 \mathrm{kyr}$ BP, during which time the abundance of this species is low.

\subsection{Oxygen stable isotope values $\left(\delta^{18} \mathrm{O}\right)$}

Single foraminiferal shell oxygen isotope values of $G$. bulloides $(n=1921)$ and $G$. truncatulinoides $(n=1933)$ show the characteristic pattern consistent with a transition between a glacial, with values enriched in $\delta^{18} \mathrm{O}$, and interglacial, with depleted $\delta^{18} \mathrm{O}$ values. Visually there is an overlap between the oxygen isotope values of all size fractions of $G$. bulloides, whereas this is only present in the larger size fractions of both G. inflata $(n=1855)$ and $G$. truncatulinoides (Figs. 4 and $5)$. For the latter two species the smaller size fraction (212$250 \mu \mathrm{m})$ appears to be relatively more depleted in $\delta^{18} \mathrm{O}$ than the larger size fractions $(250-400 \mu \mathrm{m})$. Plotting the mean, per sample, smallest $(212-250 \mu \mathrm{m})$ and largest $(355-400 \mu \mathrm{m})$ size fraction $\delta^{18} \mathrm{O}$ against each other (Fig. 6) shows that the slopes of G. bulloides, G. inflata and $G$. truncatulinoides are statistically significant from 0 ( $t$-test values for correlation coefficient: $6.5776,3.5421$ and 6.8653 , respectively, with a two-tailed test value of 2.064 at $\alpha 0.05, H_{0}: p=0$ ). However there is insufficient evidence to suggest that the value of the slope is statistically different from a $1: 1$ iso- $\delta$ line $(t$-test values for difference: $-1.305,-1.288$ and -1.669 , respectively). At the minimum value the offset between smallest and largest size fractions is $0.4535,1.5919$ and 1.8467; however, given that the slopes are $0.8033,0.5687$ and 0.8929 , this value decreases with more enriched $\delta^{18} \mathrm{O}$ values, i.e. at colder values (Fig. 6).

For $G$. bulloides only 4 out of 26 samples show sufficient evidence to reject the null hypothesis; thus for this species the size fractions have predominately the same mean values, whereas all size fractions show a statistical difference, and thus the difference between size fractions is not constant (Table 1). For $G$. inflata, 20 out of 26 samples show sufficient 


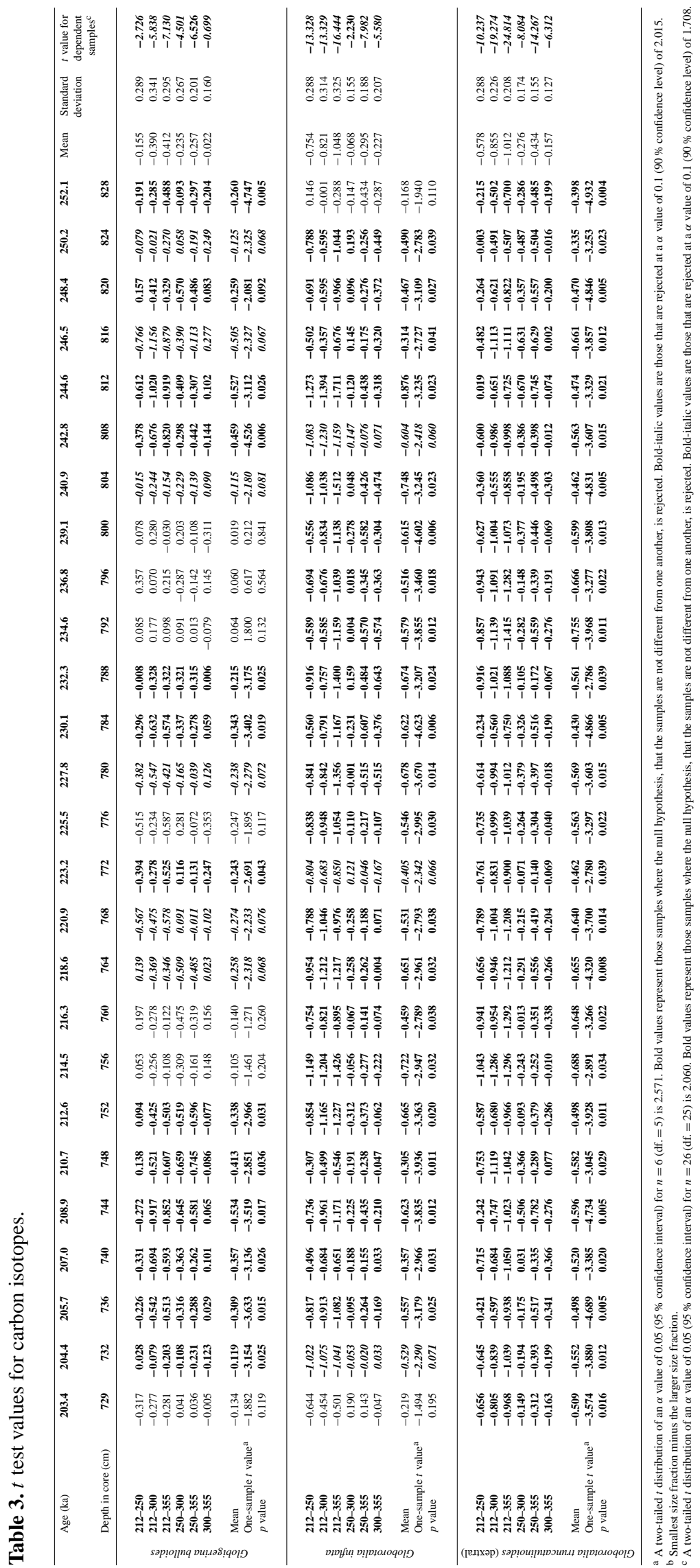




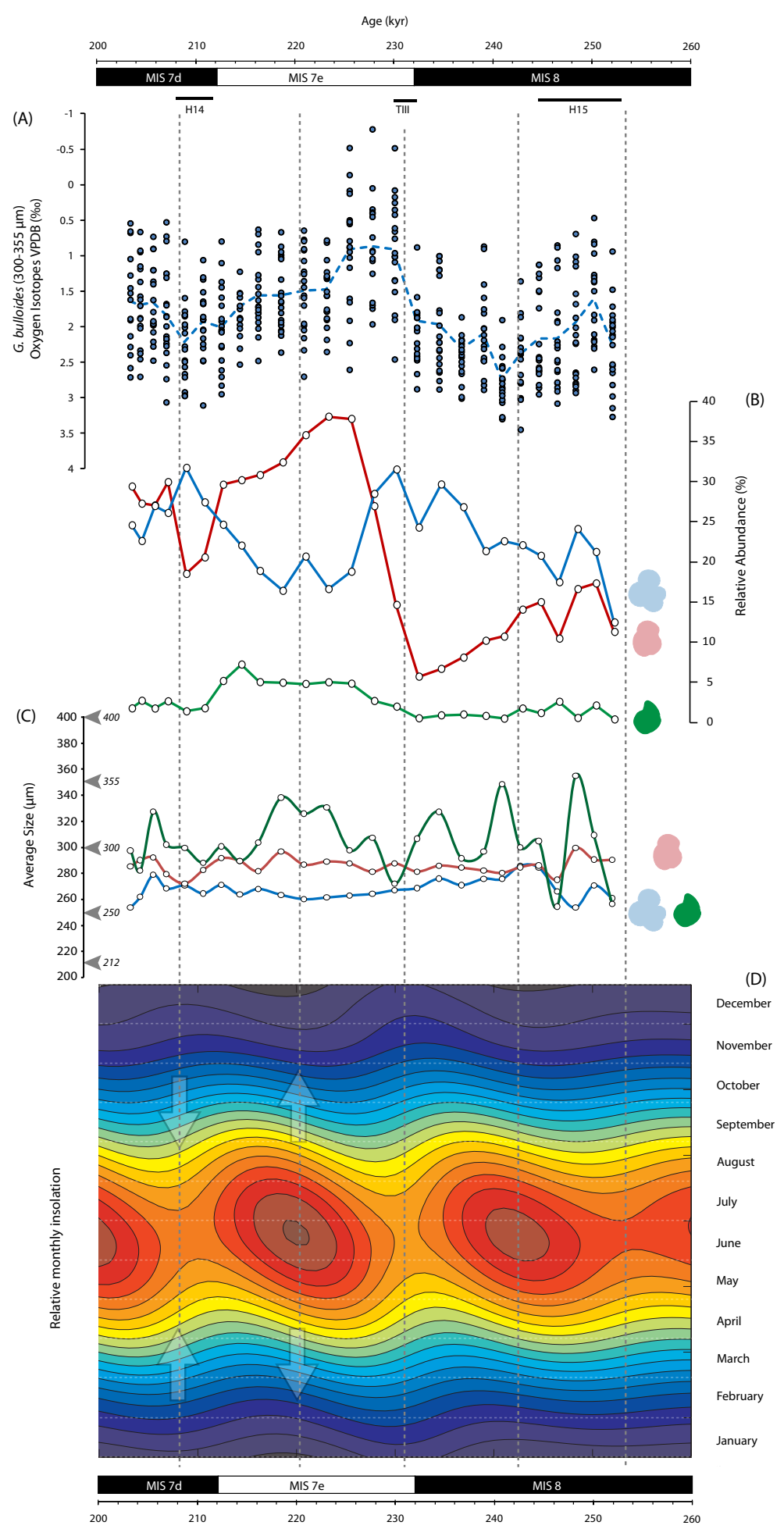

Figure 3. Relative abundance and average size of planktonic foraminifera across MIS7 to 8. (a) G. bulloides single-specimen $\delta^{18} \mathrm{O}$ values, for reference; the dashed line represents average $\delta^{18} \mathrm{O}$ values. (b) Relative abundance of the whole sample of G. bulloides (blue), G. inflata (red) and $G$. truncatulinoides (green) used to calculate the average size (c); arrows in (c) denote the upper and lower limits of the size fractions used in this study. In comparison with abundance and average size, the relative monthly insolation (d) for the time period has been plotted. Arrows in (d) represent expansion and contraction of increased summer insolation. Dashed vertical lines indicate the minima and maxima in insolation; horizontal bars at the top specify samples that contain Heinrich/IRD (ice-rafted debris). 


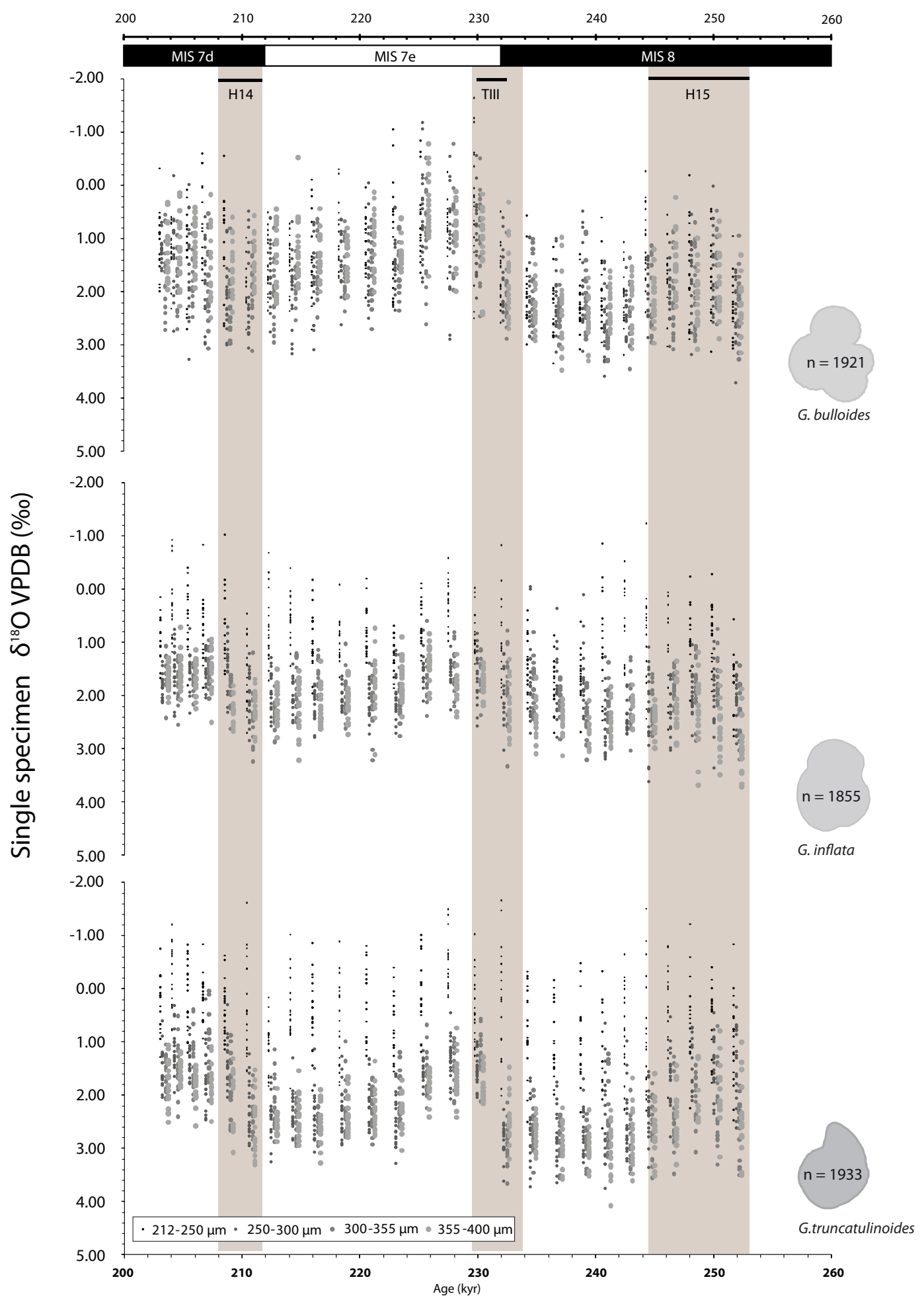

Figure 4. Single-specimen oxygen isotope values. Raw $\delta^{18} \mathrm{O}$ values; symbol size denotes size fraction. For convenience, the data points are offset from one another. Shaded regions represent periods where ice-rafted debris is present within the core; however, this envelope is larger than the actual duration of a Heinrich event, as it is difficult to constrain the precise date of such "old" events. 


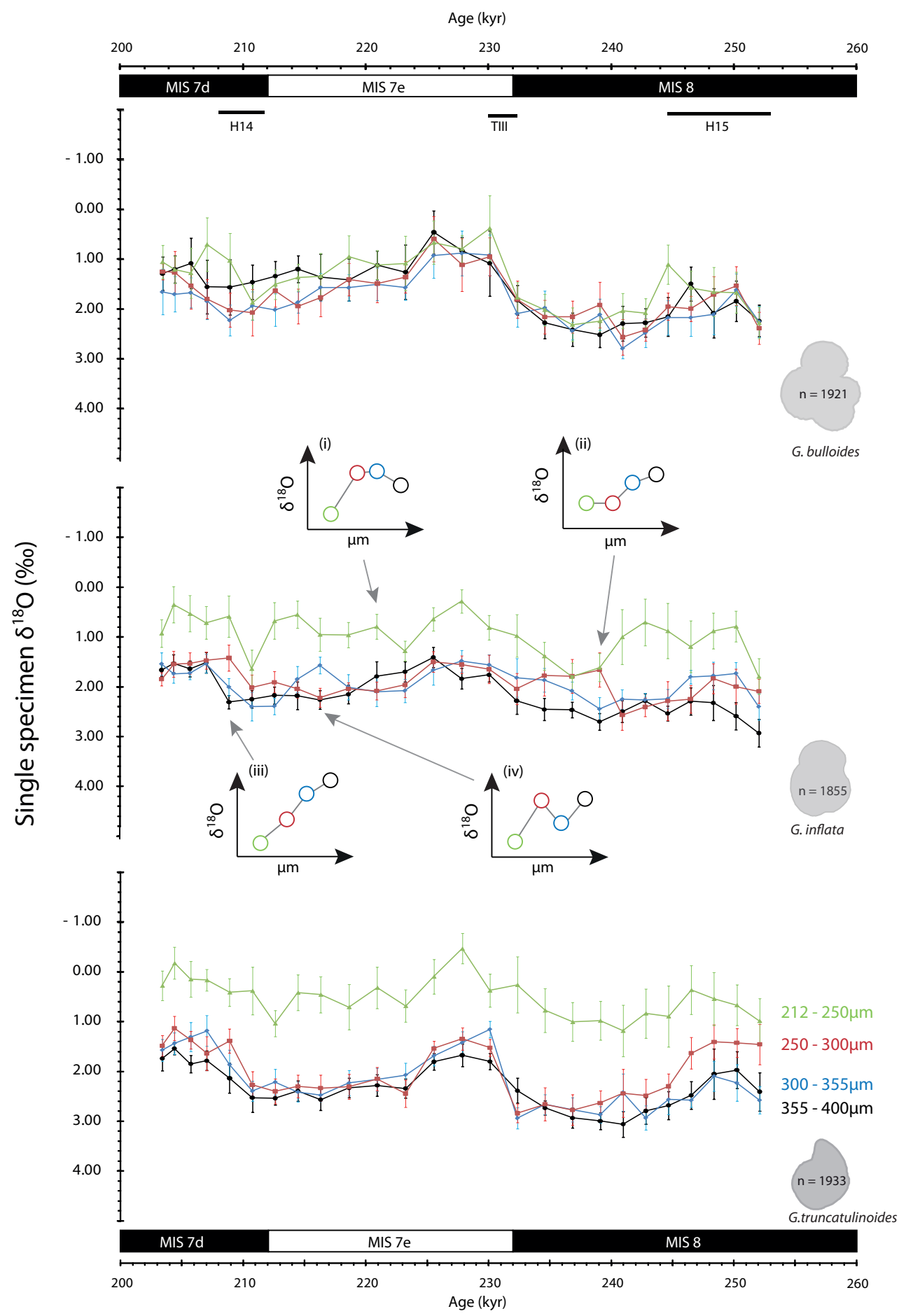

Figure 5. Mean oxygen isotope values with $95 \%$ confidence intervals. Mean $\delta^{18} \mathrm{O}$ values for (top panel) G. bulloides, (middle panel) $G$. inflata and (bottom panel) G. truncatulinoides; colour denotes size fraction. Confidence intervals are based upon using the outlier-corrected single-specimen data to compute a $t$-based confidence interval $(n<30)$ at the $95 \%$ level $(\alpha=0.05)$, assuming that the sample is normally distributed. Insets in the middle panel show the size versus oxygen isotope for (i) $220.9 \mathrm{kyr}$ BP reminiscent of the study of Ravelo and Fairbanks (1992): (ii) 239.1, (iii) 208.9 and (iv) $216.3 \mathrm{kyr} \mathrm{BP}$. A one-sample $t$ test shows that (i) and (iv) do not have sufficient evidence to reject the null hypothesis $\left(H_{0}\right)$ that the means are different, whereas (ii) and (iii) have sufficient evidence to accept the alternative hypothesis $\left(H_{1}\right)$. 
Table 4. Covariance of studied planktonic foraminifera. Test values for covariance and correlation coefficient of G. bulloides.

\begin{tabular}{|c|c|c|c|c|c|c|c|c|c|c|c|c|c|c|c|c|}
\hline \multirow{3}{*}{$\begin{array}{l}\text { Depth } \\
\text { in core } \\
(\mathrm{cm})\end{array}$} & \multirow{3}{*}{$\begin{array}{l}\text { Age } \\
(\mathrm{kyr})\end{array}$} & \multicolumn{15}{|c|}{ G. bulloides } \\
\hline & & \multicolumn{4}{|c|}{ Covariance } & \multicolumn{4}{|c|}{ Product of standard deviations } & \multicolumn{4}{|c|}{ Correlation coefficient } & \multicolumn{3}{|c|}{ Combined } \\
\hline & & $\begin{array}{c}212-250 \\
\mu \mathrm{m}\end{array}$ & $\begin{array}{c}250-300 \\
\mu \mathrm{m}\end{array}$ & $\begin{array}{c}300-355 \\
\mu \mathrm{m}\end{array}$ & $\begin{array}{c}355-400 \\
\mu \mathrm{m}\end{array}$ & $\begin{array}{c}212-250 \\
\mu \mathrm{m}\end{array}$ & $\begin{array}{c}250-300 \\
\mu \mathrm{m}\end{array}$ & $\begin{array}{c}300-355 \\
\mu \mathrm{m}\end{array}$ & $\begin{array}{c}355-400 \\
\mu \mathrm{m}\end{array}$ & $\begin{array}{c}212-250 \\
\mu \mathrm{m}\end{array}$ & $\begin{array}{c}250-300 \\
\mu \mathrm{m}\end{array}$ & $\begin{array}{c}300-355 \\
\mu \mathrm{m}\end{array}$ & $\begin{array}{c}355-400 \\
\mu \mathrm{m}\end{array}$ & Covar. & SD prod. & Corr. coef. \\
\hline 729 & 203.4 & 0.00 & -0.02 & 0.07 & 0.19 & 0.20 & 0.26 & 0.27 & 0.30 & 0.01 & -0.06 & 0.24 & 0.65 & 0.08 & 0.29 & 0.28 \\
\hline 732 & 204.4 & -0.04 & 0.01 & 0.06 & 0.09 & 0.19 & 0.39 & 0.19 & 0.36 & -0.21 & 0.02 & 0.33 & 0.26 & 0.03 & 0.30 & 0.10 \\
\hline 736 & 205.7 & -0.02 & 0.13 & 0.20 & 0.09 & 0.59 & 0.52 & 0.28 & 0.21 & -0.03 & 0.26 & 0.72 & 0.41 & 0.11 & 0.43 & 0.24 \\
\hline 740 & 207.0 & 0.48 & 0.16 & 0.16 & 0.15 & 0.72 & 0.39 & 0.29 & 0.33 & 0.67 & 0.41 & 0.55 & 0.45 & 0.34 & 0.55 & 0.61 \\
\hline 744 & 208.9 & 0.23 & -0.04 & -0.09 & 0.22 & 0.57 & 0.40 & 0.24 & 0.41 & 0.41 & -0.11 & -0.37 & 0.52 & 0.14 & 0.58 & 0.25 \\
\hline 748 & 210.7 & 0.17 & 0.24 & 0.07 & -0.04 & 0.64 & 0.48 & 0.23 & 0.18 & 0.27 & 0.50 & 0.30 & -0.20 & 0.05 & 0.44 & 0.12 \\
\hline 752 & 212.6 & -0.03 & 0.11 & 0.07 & 0.13 & 0.26 & 0.32 & 0.29 & 0.33 & -0.12 & 0.35 & 0.26 & 0.40 & 0.06 & 0.39 & 0.16 \\
\hline 756 & 214.5 & 0.00 & 0.20 & 0.12 & 0.07 & 0.19 & 0.38 & 0.21 & 0.27 & 0.00 & 0.53 & 0.57 & 0.27 & 0.09 & 0.31 & 0.28 \\
\hline 760 & 216.3 & 0.32 & 0.08 & 0.04 & 0.00 & 0.56 & 0.25 & 0.17 & 0.22 & 0.56 & 0.34 & 0.22 & -0.01 & 0.09 & 0.33 & 0.28 \\
\hline 764 & 218.6 & 0.22 & 0.09 & 0.11 & 0.20 & 0.31 & 0.31 & 0.22 & 0.32 & 0.71 & 0.28 & 0.48 & 0.64 & 0.17 & 0.32 & 0.52 \\
\hline 768 & 220.9 & 0.25 & 0.11 & -0.01 & 0.07 & 0.34 & 0.24 & 0.22 & 0.19 & 0.75 & 0.45 & -0.03 & 0.35 & 0.12 & 0.30 & 0.40 \\
\hline 772 & 223.2 & 0.37 & 0.08 & 0.02 & 0.12 & 0.63 & 0.29 & 0.24 & 0.18 & 0.58 & 0.27 & 0.09 & 0.65 & 0.14 & 0.37 & 0.39 \\
\hline 776 & 225.5 & 0.34 & 0.20 & 0.05 & 0.11 & 0.59 & 0.39 & 0.34 & 0.21 & 0.58 & 0.51 & 0.16 & 0.51 & 0.14 & 0.42 & 0.34 \\
\hline 780 & 227.8 & 0.14 & 0.07 & -0.03 & 0.02 & 0.33 & 0.40 & 0.29 & 0.21 & 0.44 & 0.17 & -0.12 & 0.08 & 0.08 & 0.34 & 0.22 \\
\hline 784 & 230.1 & 0.24 & 0.07 & 0.02 & 0.09 & 0.52 & 0.29 & 0.33 & 0.29 & 0.47 & 0.24 & 0.05 & 0.32 & 0.16 & 0.44 & 0.38 \\
\hline 788 & 232.3 & 0.08 & 0.14 & 0.01 & 0.02 & 0.24 & 0.42 & 0.34 & 0.33 & 0.32 & 0.34 & 0.04 & 0.07 & 0.07 & 0.34 & 0.21 \\
\hline 792 & 234.6 & 0.52 & -0.06 & -0.04 & 0.04 & 0.66 & 0.28 & 0.20 & 0.16 & 0.79 & -0.23 & -0.20 & 0.26 & 0.12 & 0.35 & 0.34 \\
\hline 796 & 236.8 & 0.42 & 0.17 & 0.01 & 0.02 & 0.66 & 0.41 & 0.19 & 0.26 & 0.64 & 0.42 & 0.03 & 0.09 & 0.15 & 0.39 & 0.37 \\
\hline 800 & 239.1 & 0.15 & 0.38 & 0.04 & 0.06 & 0.40 & 0.46 & 0.28 & 0.12 & 0.38 & 0.83 & 0.13 & 0.49 & 0.15 & 0.33 & 0.47 \\
\hline 804 & 240.9 & 0.27 & 0.13 & 0.00 & 0.09 & 0.53 & 0.33 & 0.13 & 0.15 & 0.51 & 0.38 & 0.01 & 0.58 & 0.14 & 0.33 & 0.43 \\
\hline 808 & 242.8 & 0.10 & 0.22 & 0.07 & 0.01 & 0.35 & 0.31 & 0.25 & 0.27 & 0.27 & 0.71 & 0.27 & 0.03 & 0.11 & 0.36 & 0.31 \\
\hline 812 & 244.6 & 0.07 & 0.15 & -0.06 & 0.07 & 0.41 & 0.24 & 0.35 & 0.24 & 0.16 & 0.64 & -0.17 & 0.28 & 0.22 & 0.47 & 0.46 \\
\hline 816 & 246.5 & 0.13 & 0.05 & 0.16 & 0.04 & 0.38 & 0.20 & 0.29 & 0.22 & 0.35 & 0.26 & 0.53 & 0.17 & 0.15 & 0.38 & 0.40 \\
\hline 820 & 248.4 & 0.00 & 0.10 & 0.08 & 0.06 & 0.57 & 0.47 & 0.44 & 0.26 & 0.01 & 0.22 & 0.19 & 0.24 & 0.10 & 0.49 & 0.20 \\
\hline 824 & 250.2 & 0.09 & -0.06 & 0.01 & -0.02 & 0.41 & 0.31 & 0.26 & 0.18 & 0.23 & -0.19 & 0.03 & -0.10 & 0.01 & 0.29 & 0.05 \\
\hline \multirow[t]{2}{*}{828} & 252.1 & -0.08 & -0.05 & 0.07 & 0.01 & 0.39 & 0.26 & 0.25 & 0.11 & -0.20 & -0.20 & 0.30 & 0.12 & -0.01 & 0.26 & -0.02 \\
\hline & & & & & & & & & Average & 0.33 & 0.28 & 0.18 & 0.29 & & Average & 0.30 \\
\hline
\end{tabular}

evidence to reject the null hypothesis; thus for this species the size fractions have predominately different mean values. When comparing whether the differences between two size fractions are equal to zero and therefore have equal means, most show a statistical difference and thus the means are not equal, nor is the offset constant through time (Table 1). Whilst visually there appears to be a difference (Fig. 5, middle panel), when viewed simply as the size-isotope relationship for a single sample, the statistical significance to either accept the alternative hypothesis (Fig. 5, middle panel, i and iv) or reject the null hypothesis (Fig. 5, middle panel, ii and iii) becomes apparent (see Supplement Figs. S1-S6). For $G$. truncatulinoides, 25 out of 26 samples show sufficient evidence to reject the null hypothesis; thus for this species the size fractions have predominately different mean $\delta^{18} \mathrm{O}$ values, whereas all size fractions show a statistical difference and thus the difference between size fractions is not constant (Table 1). Curiously, the means of small specimens of $G$. inflata and G. truncatulinoides are more depleted and show differences from those of coeval small specimens of $G$. bulloides. This is not present in the other, larger size fractions.

Comparison of the spread, using the standard deviation per size fraction (Fig. S7-S8), in G. bulloides against the insolation difference between July and December reveals a negative correlation, with larger insolation differences associated with a lower standard deviation. The relationship is stronger $(r=0.5748)$, however, when the insolation difference between the months associated with the end of the deep winter mixing and summer stratification (March and June) in the modern ocean are used. It would appear that when the $\Delta \delta^{18} \mathrm{O}$ between small and large $G$. inflata $\left(\Delta \delta^{18} \mathrm{O}_{\mathrm{s}-1}\right)$ is reduced, so that the smallest specimens of $G$. inflata have similar values to larger specimens $(>250 \mu \mathrm{m})$, insolation is halfway between a minimum and maximum, apart from at 234-239 kyr BP during the onset of the termination. During these transient events the $\delta^{18} \mathrm{O}$ of $G$. inflata shows a relationship with the $\delta^{18} \mathrm{O}$ of the largest size fraction (355$400 \mu \mathrm{m})$ of $G$. bulloides $\left(r^{2}=0.4935 ; n=8\right)$. Given that these events occur in relationship to the insolation, the first derivative of the seasonal difference at $45^{\circ} \mathrm{N}$ was taken as the magnitude and direction of change in seasonality and compared with $\Delta \delta^{18} \mathrm{O}_{\mathrm{s}-1}$ for $G$. inflata. This reveals that there is a linear relationship that positively correlates during MIS8 ( $r=0.6538)$ and negatively correlates during interglacial MIS7 $(r=0.6882)$.

\subsection{Carbon stable isotope values $\left(\delta^{13} \mathrm{C}\right)$}

In contrast with $\delta^{18} \mathrm{O}$, the $\delta^{13} \mathrm{C}$ of the means of the smallestsized specimens have a larger range than that of the largestsized specimens. Carbon isotope values are generally lower in the smaller size fractions of $G$. inflata and $G$. truncatulinoides (although this pattern is not consistent throughout the record) than the largest size fraction (Table 2, Fig. 6). There is, however, an overlap between the mean $\delta^{13} \mathrm{C}$ values of the smallest-sized specimens of different species. G. bulloides has a less discernible trend; there are only 2 samples, out of 26 , where the smallest size fraction of $G$. bulloides appears to deviate from the others, i.e. at 244 and 246 kyr BP (Fig. 8). 

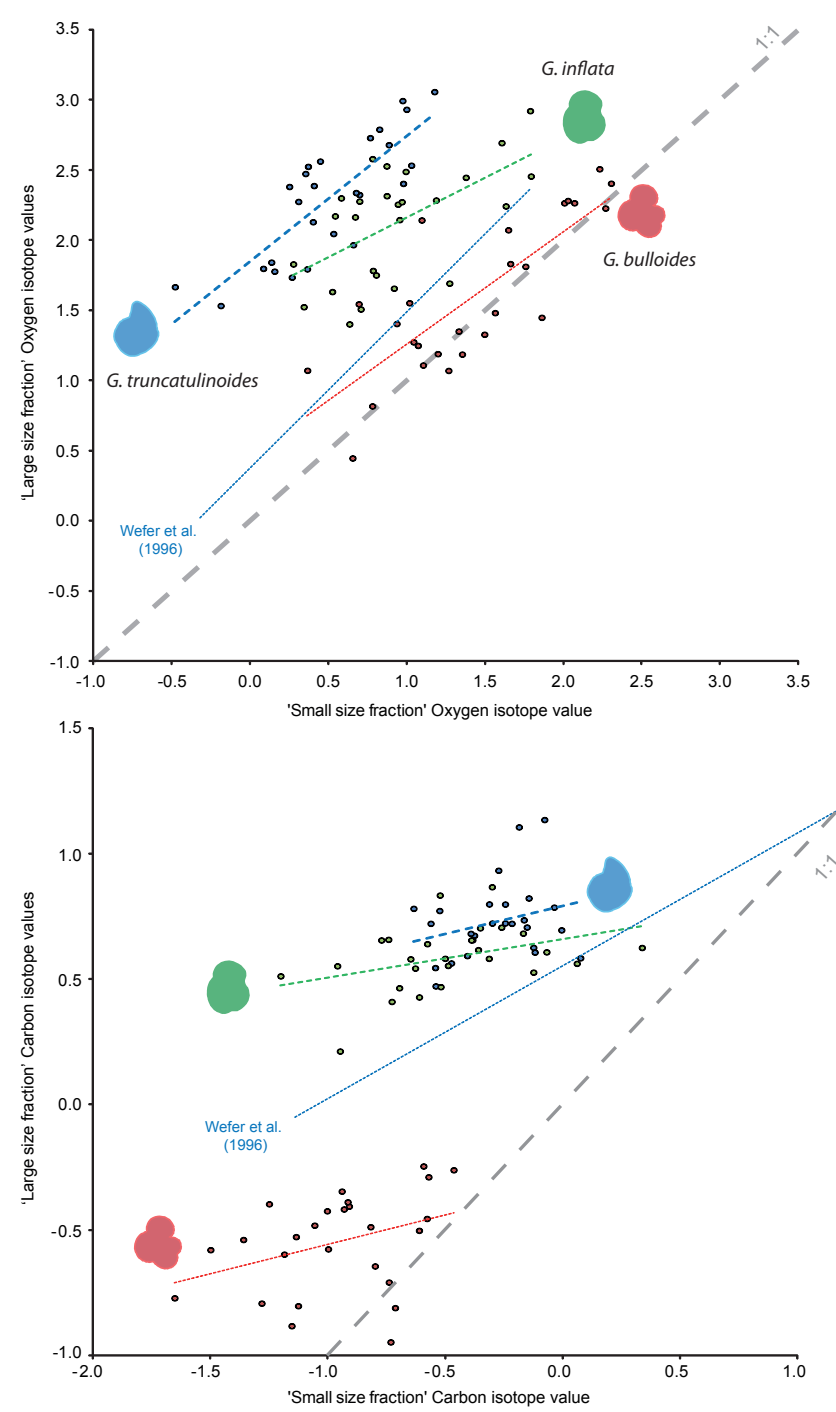

Figure 6. Isotope differences for each species between the smallest and largest size fraction. Isotope difference between the mean of the smallest $(212-250 \mu \mathrm{m})$ and largest $(355-400 \mu \mathrm{m})$ size fractions of (top panel) $\delta^{18} \mathrm{O}$ and (bottom panel) $\delta^{13} \mathrm{C}$. The $1: 1$ ( $\delta$-iso line) relationship (grey dashed line) is presented to compare the linear regressions (coloured dashed lines). For the equations of each linear regression and the resultant $t$-test values, see Table 4 . The $\delta$-iso lines of $G$. truncatulinoides from Wefer et al. (1996) are presented for comparison.

In comparison, only the samples at 246 and $252 \mathrm{kyr} \mathrm{BP}$ show similar isotope values between all size fractions (Fig. 8).

Statistically the within-sample size fraction differences show that 19 of the G. bulloides samples (6 are at the $90 \%$ confidence interval and 13 are at $95 \%$ ), 24 of the G. inflata (3 are at the $90 \%$ confidence interval and 21 are at $95 \%$ ) and 26 of the G. truncatulinoides (26 are at the $95 \%$ confidence level) are significantly different at, and above, the $90 \%$ confidence level (Table 3). Small $(212-250 \mu \mathrm{m})$ specimens of surface-dwelling G. bulloides and intermediate $G$. inflata have a larger range in mean $\delta^{13} \mathrm{C}$ than larger specimens (Figs. 7 and 8). Curiously the relationship between size and $\delta^{13} \mathrm{C}$ is strikingly different from the relationship for $\delta^{18} \mathrm{O}$; the large offset in oxygen between specimens from $212-250 \mu \mathrm{m}$ and specimens from $250-300 \mu \mathrm{m}$ for $G$. truncatulinoides is not visible in the carbon isotope record. The results of the $t$ test for dependent samples shows that all are statistically significantly different at the $95 \%$ confidence level, suggesting that the offset between size fractions is not constant (Table 3).

\subsection{Covariance}

Interdependence between $\delta^{18} \mathrm{O}$ and $\delta^{13} \mathrm{C}$ (Tables 4 and 5) is visualised in a cross-plot (Fig. 9). On average both $G$. bulloides and $G$. inflata show a decreasing correlation coefficient with size between 212 and $355 \mu \mathrm{m}$. Both, however, show a reversal of this trend towards the largest size fraction (355-400 $\mu \mathrm{m}$; Tables 4 and 5). The average correlation coefficient shows no variation consistent with changes between the glacial and interglacial, although $G$. bulloides shows marginally lower values during H14, H15 and TIII, and all species have their lowest correlation coefficient at $250 \mathrm{kyr}$ BP. G. bulloides has considerably more depleted values in $\delta^{13} \mathrm{C}$ than the other species of planktonic foraminifera, whilst smaller specimens of $G$. inflata overlap the area covered by all sizes of G. bulloides. Peculiarly, small-sized specimens of G. truncatulinoides have on occasion more depleted values of $\delta^{18} \mathrm{O}$ than the other species, for a similar size.

\section{Discussion}

\subsection{Size-isotope relationship}

In this paper we applied multiple individual specimen analysis (ISA) to the problem of the size-isotope relationship to more than one sample to assess whether (1) there is a significant correlation between size and stable isotopes, and if so, (2) whether the relationship remains constant through time over a large climatic perturbation, i.e. glacial Termination III. Previous studies testing the relationship between shell size and the isotopic signal have shown systematic differences between both oxygen and carbon isotopes (Berger et al., 1978; Billups and Spero, 1995; Kroon and Darling, 1995) (Fig. 10). This represents a logical partitioning between the isotopes of the two elements carbon and oxygen: carbon isotopes predominately represent biotic processes such as productivity as a function of metabolic rates and nutrient concentrations, as well as being influenced by the photo-auto/heterotrophic symbionts that some species of foraminifera host. They can also represent the abiotic, i.e. ventilation of oceanic water masses and or carbonate ion concentrations (Spero et al., 1997). Oxygen isotope values are primarily influenced by abiotic factors such as glacioeustatic/ice volume, local hydrographic evaporation/precipitation, and temperature. At a 


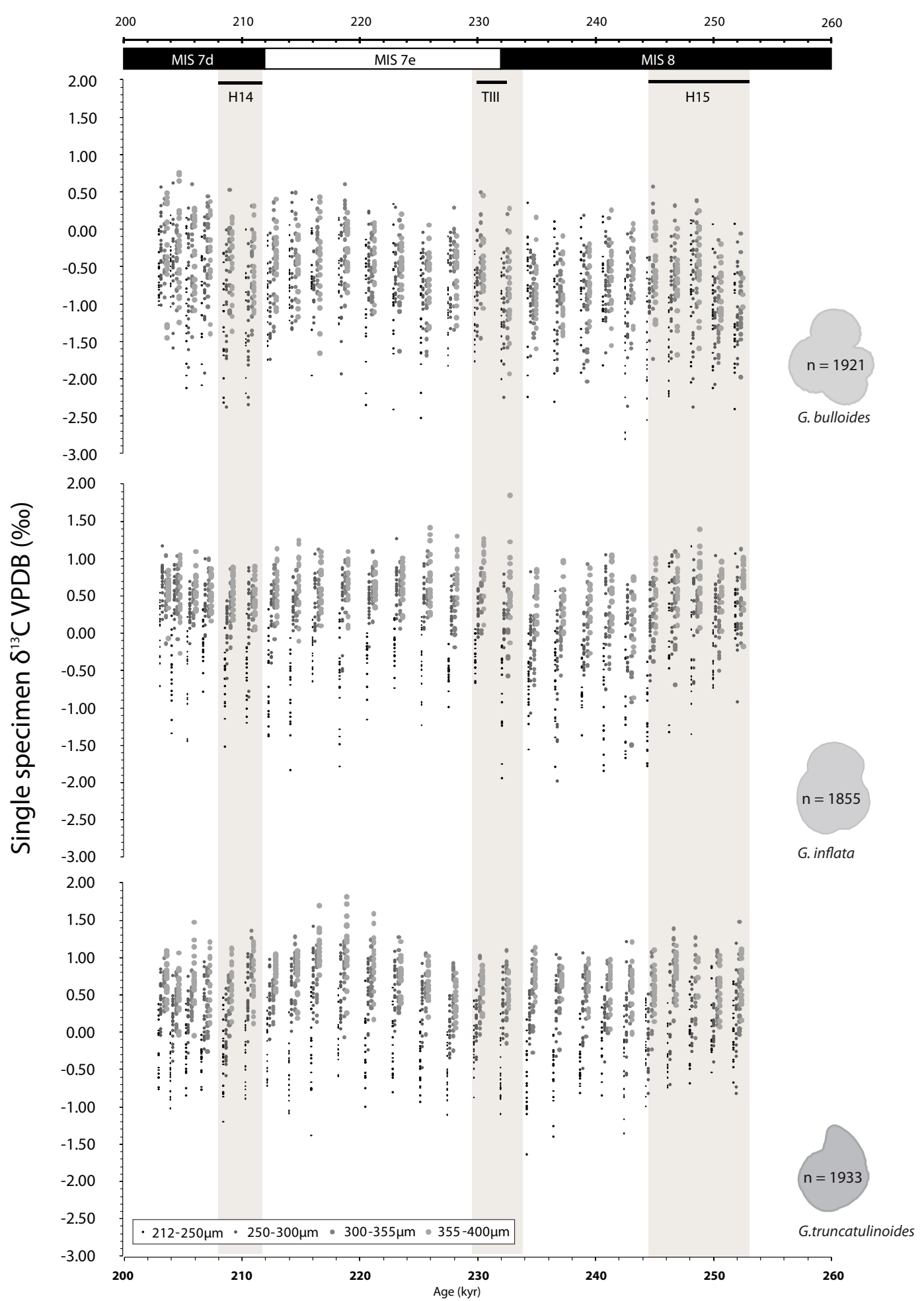

Figure 7. Single-specimen carbon isotope values. Raw $\delta^{13} \mathrm{C}$ values; symbol size denotes size fraction. For convenience, the data points are offset from one another. Highlighted regions represent the glacial and interglacial Heinrich events (H14 and H15) and Termination III. 


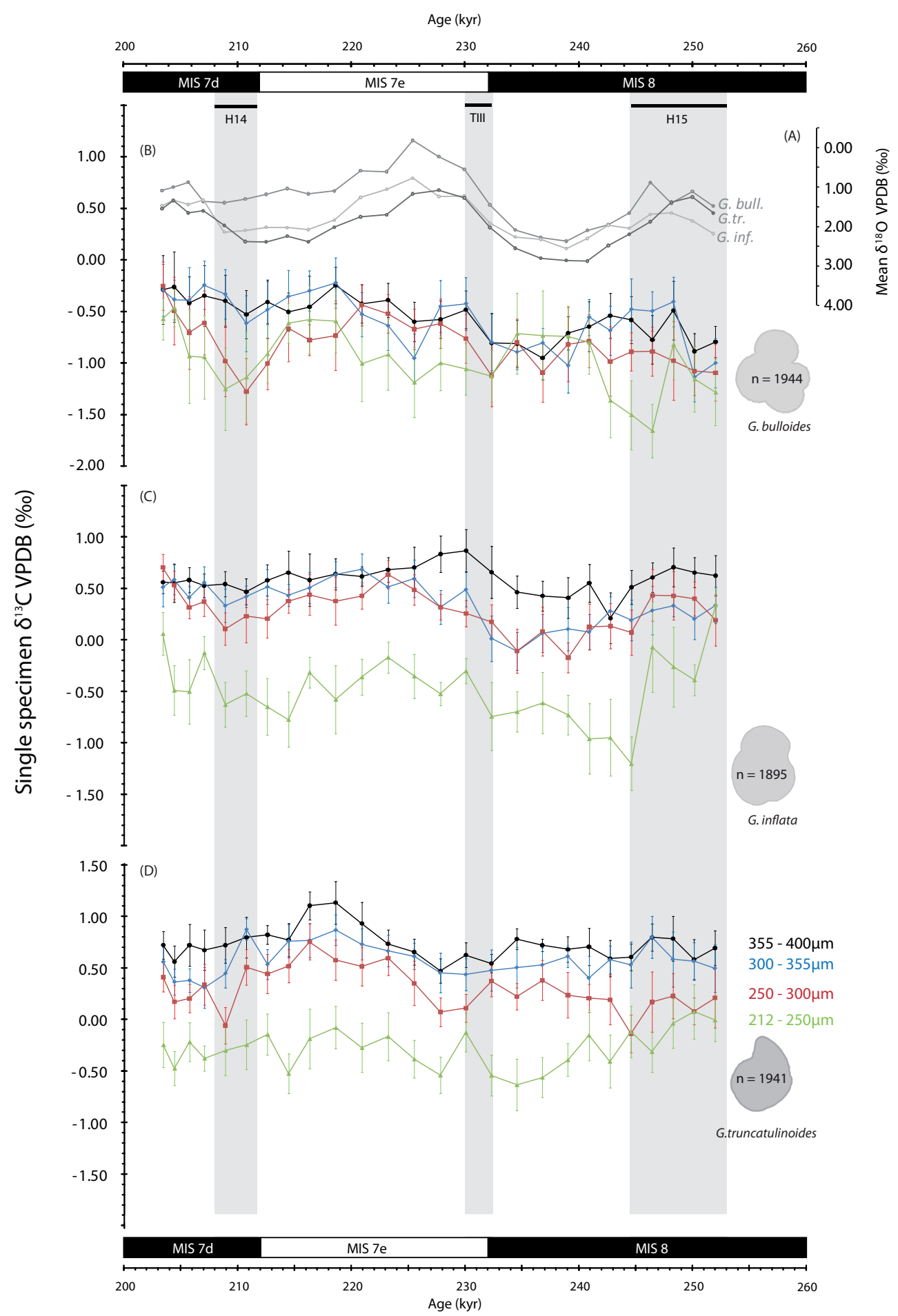

Figure 8. Mean carbon isotope values with $95 \%$ confidence intervals. (a) For comparative purposes the mean $\delta^{18} \mathrm{O}$ values for G. bulloides, G. inflata and G. truncatulinoides are shown. Mean $\delta^{13} \mathrm{C}$ values for (b) G. bulloides, (c) G. inflata and (d) G. truncatulinoides; colour denotes size fraction. Highlighted regions represent the glacial and interglacial Heinrich events (H14 and H15) and Termination III. 

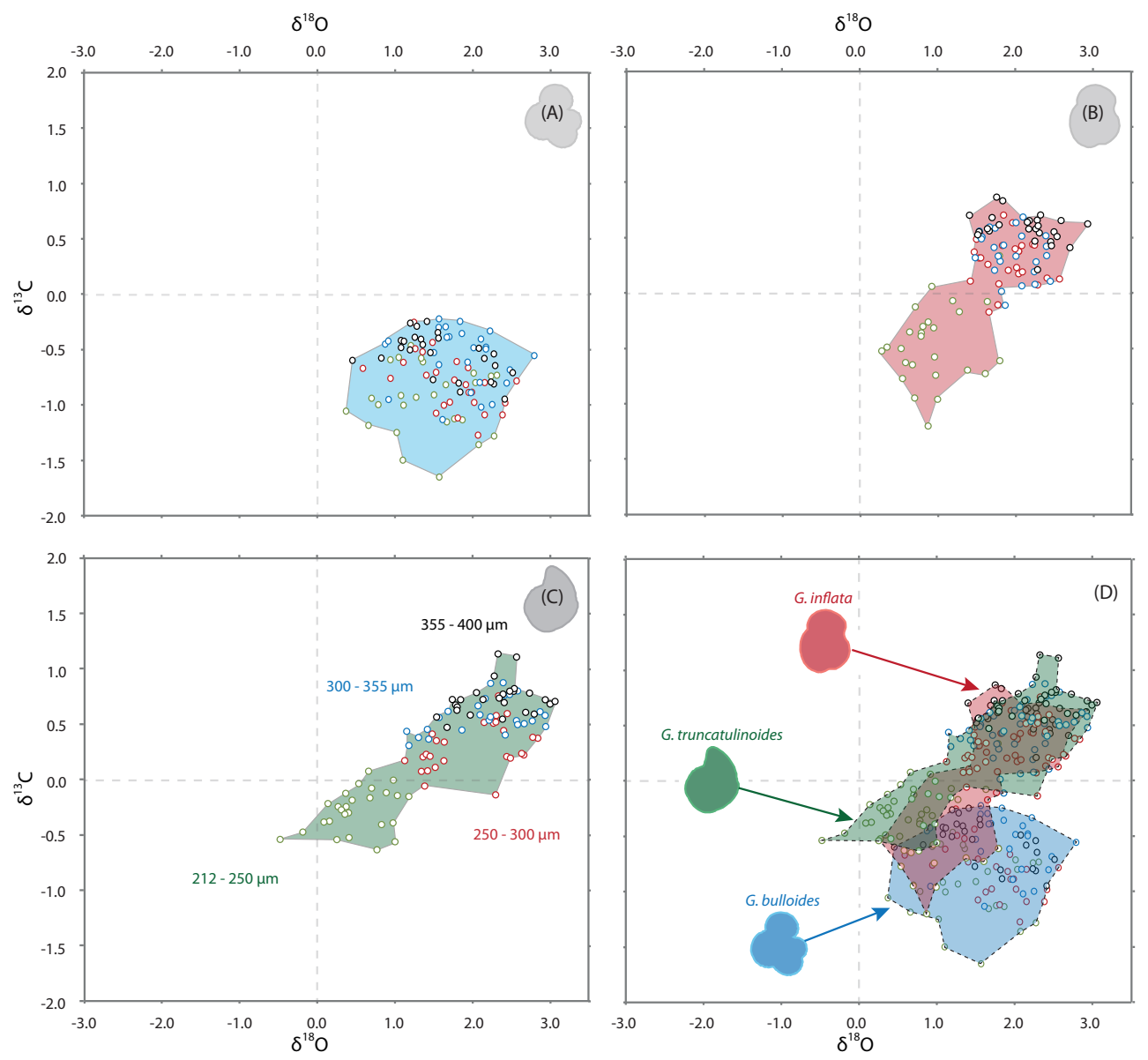

Figure 9. Cross-plot of oxygen and carbon values. Cross-plot between mean $\delta^{18} \mathrm{O}$ and $\delta^{13} \mathrm{C}$ for all size fractions of (a) G. bulloides, (b) G. inflata, (c) G. truncatulinoides and (d) all species. For (a)-(c), symbol colour represents size fraction as per Figs. 5 and 8: 212-250 (green), 250-300 (red), 300-355 (blue) and 355-400 $\mu \mathrm{m}$ (black).

cursory glance our results show that larger specimens of both $G$. inflata and G. truncatulinoides are enriched in both ${ }^{18} \mathrm{O}$ and ${ }^{13} \mathrm{C}$ compared to smaller specimens, although this relationship is only constant for $G$. truncatulinoides. Whilst specimens of $G$. bulloides show no significant variation with size for ${ }^{18} \mathrm{O}$, with small and large specimens showing a near identical isotope trend across Termination III, there is a progressive enrichment in ${ }^{13} \mathrm{C}$ with increasing size. Berger et al. (1978) considered that the size-isotope relationship can be broadly grouped into three categories: (1) "normal", in which progressively larger sizes are more enriched; (2) "reversed" in which larger sizes are more depleted; and (3) "mixed", in which no clear trend can be deduced, for both $\delta^{18} \mathrm{O}$ and $\delta^{13} \mathrm{C}$. The results presented here show that $G$. bulloides and G. inflata vary between "normal" and "mixed", whilst only G. truncatulinoides shows a consistent "normal" trend (see Figs. S1-S6).

With respect to the "normal" trend Berger (1979) considered four possible explanations for an enrichment in oxygen isotope composition with increasing size: (i) size is related to physical parameters, i.e. temperature (Schmidt et al., 2006), and thus larger specimens relate to optimum conditions (Bé and Lott, 1964; Bé et al., 1966; Berger, 1971); (ii) the degree of isotopic disequilibrium in calcification changes with growth (Vergnaud-Grazzini, 1976) and/or physical parameters (i.e. temperature); (iii) growth-related depth change with smaller individuals being found in greater concentrations closer to the surface - the implication being that small shells are prematurely (i.e. pre-reproduction) terminated individuals (Emiliani, 1954, 1971); (iv) adults that sink but do not reproduce continue to calcify giving a more enriched $\delta^{18} \mathrm{O}$ signal (Fig. 11). "Mixed" trends however pose a problem in explaining oxygen isotopes solely related to growthrelated depth change. If it is considered that the transition from juvenile-neanic to adult stages occurs between 100 and $200 \mu \mathrm{m}$ (Brummer et al., 1987), then all specimens above $200 \mu \mathrm{m}$ are adult. The shape of the size frequency distribution of the pre-adult population is exponential, whereas in comparison the adult population has a distinct Gaussian shape (Brummer et al., 1986, 1987; Peeters et al., 1999), which 

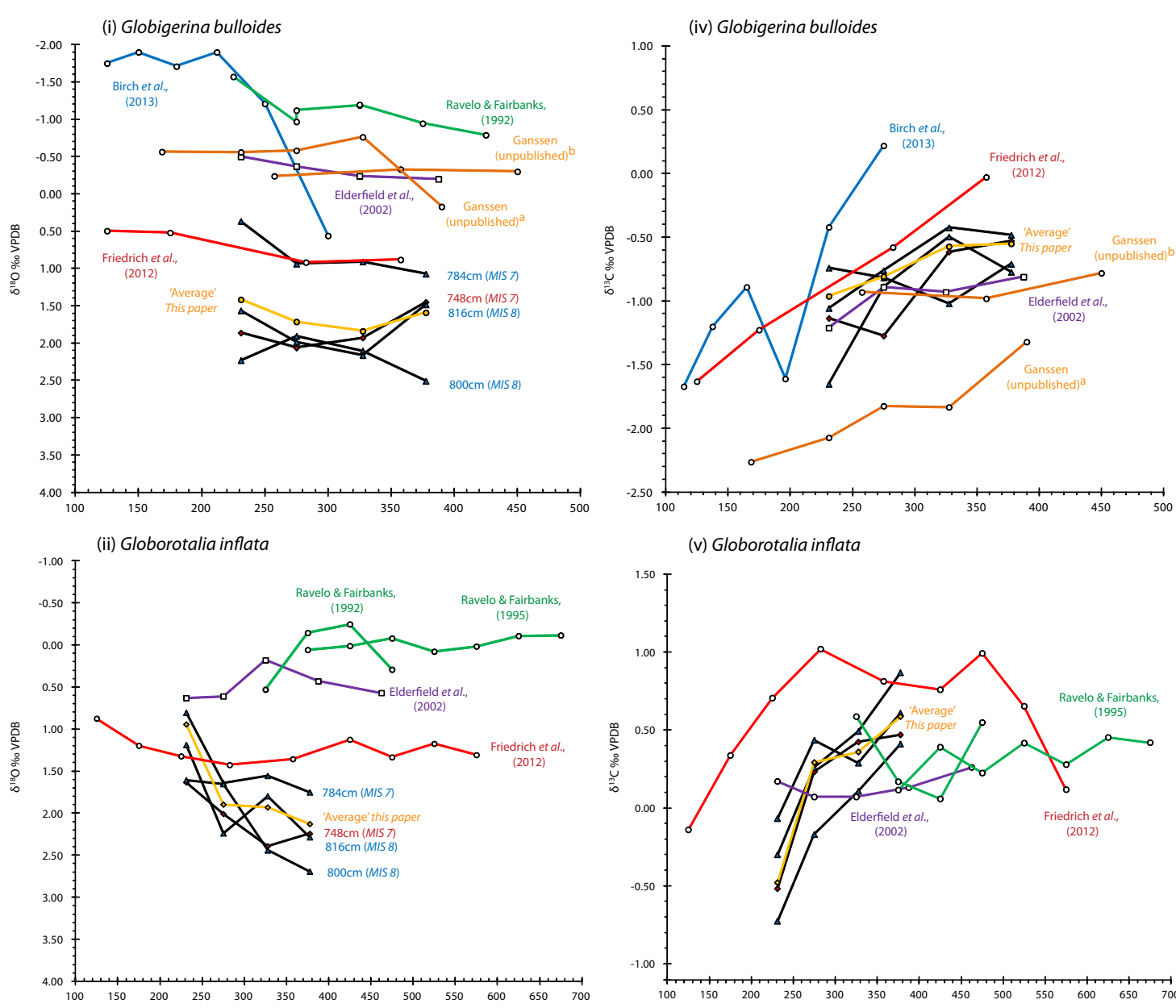

(v) Globorotalia inflata
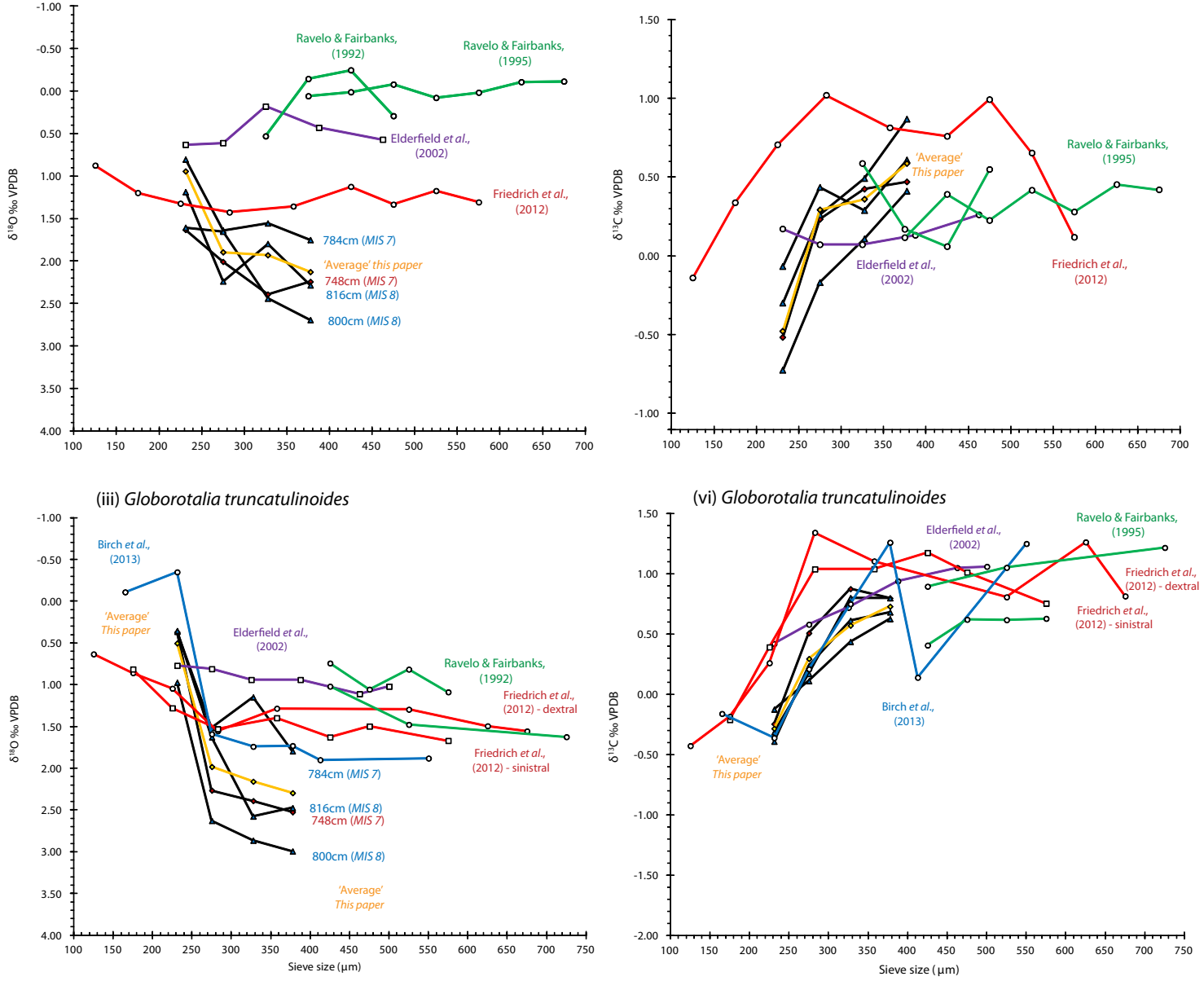

Figure 10. Previous size-isotope relationship. Previously published size-isotope trends (i-iii) $\delta^{18} \mathrm{O}$ and (iv-vi) $\delta^{13} \mathrm{C}$ compared with four samples that represent, based upon the ratio between Neogloboquadrina pachyderma and $N$. incompta (unpublished data), cold and warm periods of MIS 8 and MIS 7. Additionally, an average size-isotope curve was constructed for comparison. Unpublished work of Ganssen from Indian Ocean core samples. 
Table 5. Covariance of studied planktonic foraminifera. Test values for covariance and correlation coefficient of $G$. inflata.

\begin{tabular}{|c|c|c|c|c|c|c|c|c|c|c|c|c|c|c|c|c|}
\hline \multirow{3}{*}{$\begin{array}{l}\text { Depth } \\
\text { in core } \\
(\mathrm{cm})\end{array}$} & \multirow{3}{*}{$\begin{array}{l}\text { Age } \\
(\mathrm{kyr})\end{array}$} & \multicolumn{15}{|c|}{ G. inflata } \\
\hline & & \multicolumn{4}{|c|}{ Covariance } & \multicolumn{4}{|c|}{ Product of standard deviations } & \multicolumn{4}{|c|}{ Correlation coefficient } & \multicolumn{3}{|c|}{ Combined } \\
\hline & & $\begin{array}{c}212-250 \\
\mu \mathrm{m}\end{array}$ & $\begin{array}{c}250-300 \\
\mu \mathrm{m}\end{array}$ & $\begin{array}{c}300-355 \\
\mu \mathrm{m}\end{array}$ & $\begin{array}{c}355-400 \\
\mu \mathrm{m}\end{array}$ & $\begin{array}{c}212-250 \\
\mu \mathrm{m}\end{array}$ & $\begin{array}{c}250-300 \\
\mu \mathrm{m}\end{array}$ & $\begin{array}{c}300-355 \\
\mu \mathrm{m}\end{array}$ & $\begin{array}{c}355-400 \\
\mu \mathrm{m}\end{array}$ & $\begin{array}{c}212-250 \\
\mu \mathrm{m}\end{array}$ & $\begin{array}{c}250-300 \\
\mu \mathrm{m}\end{array}$ & $\begin{array}{c}300-355 \\
\mu \mathrm{m}\end{array}$ & $\begin{array}{c}355-400 \\
\mu \mathrm{m}\end{array}$ & Covar. & SD prod. & Corr. coef. \\
\hline 729 & 203.4 & 0.18 & 0.04 & 0.00 & 0.01 & 0.26 & 0.08 & 0.14 & 0.05 & 0.67 & 0.47 & 0.01 & 0.24 & 0.17 & 0.24 & 0.69 \\
\hline 732 & 204.4 & 0.13 & 0.04 & -0.02 & 0.06 & 0.26 & 0.16 & 0.09 & 0.11 & 0.51 & 0.22 & -0.18 & 0.55 & 0.29 & 0.39 & 0.74 \\
\hline 736 & 205.7 & 0.25 & 0.07 & 0.01 & 0.06 & 0.30 & 0.13 & 0.07 & 0.08 & 0.84 & 0.52 & 0.17 & 0.70 & 0.26 & 0.33 & 0.81 \\
\hline 740 & 207.0 & 0.15 & 0.02 & 0.06 & 0.00 & 0.25 & 0.11 & 0.10 & 0.08 & 0.60 & 0.15 & 0.56 & -0.04 & 0.14 & 0.24 & 0.60 \\
\hline 744 & 208.9 & 0.18 & 0.07 & 0.00 & 0.03 & 0.27 & 0.16 & 0.14 & 0.09 & 0.67 & 0.43 & -0.03 & 0.32 & 0.34 & 0.44 & 0.76 \\
\hline 748 & 210.7 & 0.28 & 0.10 & 0.07 & 0.01 & 0.38 & 0.29 & 0.19 & 0.07 & 0.73 & 0.34 & 0.36 & 0.10 & 0.16 & 0.28 & 0.56 \\
\hline 752 & 212.6 & 0.23 & 0.05 & 0.02 & 0.04 & 0.34 & 0.13 & 0.08 & 0.09 & 0.67 & 0.42 & 0.20 & 0.43 & 0.42 & 0.49 & 0.84 \\
\hline 756 & 214.5 & 0.18 & 0.02 & 0.01 & 0.11 & 0.27 & 0.10 & 0.08 & 0.18 & 0.68 & 0.20 & 0.17 & 0.60 & 0.46 & 0.54 & 0.84 \\
\hline 760 & 216.3 & 0.24 & 0.47 & 0.02 & 0.05 & 0.35 & 0.60 & 0.07 & 0.16 & 0.69 & 0.79 & 0.21 & 0.30 & 0.40 & 0.56 & 0.71 \\
\hline 764 & 218.6 & 0.44 & 0.28 & 0.02 & 0.07 & 0.51 & 0.52 & 0.15 & 0.10 & 0.87 & 0.55 & 0.11 & 0.70 & 0.49 & 0.61 & 0.80 \\
\hline 768 & 220.9 & 0.17 & 0.03 & 0.01 & 0.03 & 0.24 & 0.09 & 0.12 & 0.09 & 0.71 & 0.29 & 0.07 & 0.36 & 0.30 & 0.40 & 0.75 \\
\hline 772 & 223.2 & 0.21 & 0.04 & 0.06 & 0.02 & 0.25 & 0.14 & 0.10 & 0.08 & 0.83 & 0.30 & 0.57 & 0.26 & 0.20 & 0.29 & 0.68 \\
\hline 776 & 225.5 & 0.16 & 0.05 & 0.05 & 0.09 & 0.24 & 0.16 & 0.12 & 0.16 & 0.65 & 0.29 & 0.45 & 0.57 & 0.28 & 0.39 & 0.73 \\
\hline 780 & 227.8 & 0.08 & 0.04 & 0.07 & 0.01 & 0.13 & 0.12 & 0.18 & 0.08 & 0.59 & 0.31 & 0.39 & 0.08 & 0.36 & 0.46 & 0.78 \\
\hline 784 & 230.1 & 0.11 & 0.02 & 0.02 & 0.03 & 0.20 & 0.11 & 0.08 & 0.12 & 0.54 & 0.16 & 0.20 & 0.28 & 0.23 & 0.34 & 0.69 \\
\hline 788 & 232.3 & 0.37 & 0.01 & 0.09 & 0.06 & 0.55 & 0.17 & 0.26 & 0.27 & 0.67 & 0.03 & 0.33 & 0.23 & 0.41 & 0.57 & 0.72 \\
\hline 792 & 234.6 & 0.10 & 0.08 & 0.05 & -0.01 & 0.19 & 0.29 & 0.19 & 0.11 & 0.56 & 0.28 & 0.28 & -0.12 & 0.21 & 0.36 & 0.58 \\
\hline 796 & 236.8 & 0.24 & 0.11 & 0.00 & 0.05 & 0.36 & 0.56 & 0.11 & 0.12 & 0.67 & 0.20 & -0.01 & 0.42 & 0.20 & 0.51 & 0.39 \\
\hline 800 & 239.1 & 0.23 & 0.40 & 0.02 & 0.11 & 0.55 & 0.54 & 0.19 & 0.14 & 0.42 & 0.75 & 0.08 & 0.78 & 0.39 & 0.61 & 0.64 \\
\hline 804 & 240.9 & 0.34 & 0.03 & 0.01 & 0.10 & 0.52 & 0.21 & 0.18 & 0.24 & 0.66 & 0.12 & 0.06 & 0.42 & 0.42 & 0.60 & 0.70 \\
\hline 808 & 242.8 & 0.39 & 0.16 & -0.02 & 0.03 & 0.45 & 0.26 & 0.12 & 0.10 & 0.86 & 0.62 & -0.17 & 0.30 & 0.45 & 0.58 & 0.78 \\
\hline 812 & 244.6 & 0.35 & 0.20 & 0.14 & 0.01 & 0.46 & 0.29 & 0.23 & 0.10 & 0.75 & 0.70 & 0.60 & 0.09 & 0.60 & 0.72 & 0.82 \\
\hline 816 & 246.5 & 0.27 & 0.02 & 0.01 & -0.03 & 0.54 & 0.19 & 0.11 & 0.13 & 0.51 & 0.08 & 0.05 & -0.23 & 0.15 & 0.33 & 0.45 \\
\hline 820 & 248.4 & 0.37 & 0.04 & 0.00 & 0.08 & 0.48 & 0.24 & 0.09 & 0.21 & 0.77 & 0.15 & -0.02 & 0.37 & 0.29 & 0.43 & 0.68 \\
\hline 824 & 250.2 & 0.07 & 0.04 & 0.03 & 0.03 & 0.15 & 0.17 & 0.18 & 0.13 & 0.45 & 0.25 & 0.17 & 0.25 & 0.30 & 0.41 & 0.72 \\
\hline \multirow[t]{2}{*}{828} & 252.1 & 0.01 & 0.02 & 0.08 & 0.10 & 0.27 & 0.27 & 0.21 & 0.18 & 0.04 & 0.07 & 0.39 & 0.54 & 0.11 & 0.35 & 0.30 \\
\hline & & & & & & & & & Average & 0.64 & 0.33 & 0.19 & 0.33 & & Average & 0.68 \\
\hline
\end{tabular}

suggests that adult specimens that are larger than the mean should be considered giants and those specimens smaller than the mean as dwarfs (Berger, 1971). It has been shown that tropical species increase in size with warmer waters, whereas polar species are larger in colder waters (Stone, 1956; Kennett, 1968; Bé et al., 1973; Hecht, 1974; Hecht et al., 1976; Schmidt et al., 2006), favourable conditions between seasons may explain a "mixed" signal. The oxygen isotope data presented in this paper will be discussed with respect to these possibilities in the following sections.

\subsection{Size of planktonic foraminifera}

Whilst the faunal transition from the glacial MIS8 to interglacial MIS7 shows the characteristic pattern associated with a warming climate, and despite a moderate increase in size occurring during the glacial period (234-252 kyr BP; Fig. 3), the changes in abundance are not concurrent in size or magnitude, with any variation in the isotopic composition in $G$. bulloides between size fractions. Likewise, no pattern can be discerned in either G. inflata or G. truncatulinoides, which, whilst displaying a (predominately) statistically significant isotopic offset between the difference size fractions and/or change in average size through time, are not correlatable. If one considers that the modern size of foraminifera is related to a number of factors, including temperature and productivity, then the modern size of foraminifera is related to the modern oceanographic regime. At present this regime is composed of a cyclonic and anticyclonic gyre system, controlling and maintaining the continued existence of the as- sociated water masses. During glacials the North Atlantic is surrounded by continental ice sheets which are inferred to extend down to the $40^{\circ} \mathrm{N}$ in the west and $50^{\circ} \mathrm{N}$ to the east (McIntyre et al., 1976); as such no analogue to the mixing of water masses synonymous with the modern Gulf StreamNorth Atlantic Drift water via cyclonic and anticyclonic eddies (McIntyre et al., 1976) occurs, as polar water masses extended as far south as $45^{\circ} \mathrm{N}$. In the modern ocean, $G$. bulloides has its largest size at $50^{\circ} \mathrm{N}$. If one is to consider that a compression or elimination of certain transitional water masses occurs during glacial periods, then this maximum size should be centred at or to the south of the location of the studied core, i.e. a size decrease should be observable at our core location. However, the control on size is not as clearly known for non-symbiotic species as it is for symbiont-bearing species. Whilst temperature may play an important role, the dynamics of the upper water column, such as the strength of winter mixing or the spring transition from a well-mixed to stratified water column, have been linked to certain seasonal successions between species (Wolfteich, 1994; Ganssen and Kroon, 2000; Salmon et al., 2015). In the modern North Atlantic, late winter deep mixing supplies the surface layer with, on average, approximately $8 \mu \mathrm{mol} \mathrm{L}^{-1}$ of nitrate and $6 \mu \mathrm{mol} \mathrm{L}{ }^{-1}$ of silicate; the rise in insolation triggers the development of the thermocline, which, in combination with a rapidly shoaling nutricline into the euphotic zone, generates the spring bloom of phytoplankton (Broerse et al., 2000). For the modern ocean, a proxy for stratification, introduced by Lototskaya and Ganssen (1998) using the 
same core presented here, was deduced from a north-south transect of box-core tops in the North Atlantic (Ganssen and Kroon, 2000). Based upon the investigation of the modern latitudinal variability in planktonic foraminiferal stable isotopes, they observed that $G$. bulloides dwells at a shallower depth than $G$. inflata. Hence, the difference $\left(\Delta \delta^{18} \mathrm{O}\right)$ between these surface and subsurface dwellers can be converted into an approximate temperature difference by taking into account that a change of approximately $-0.22 \%$ occurs per degree Celcius increase. When this difference equals (or approaches) zero, such as in the modern ocean at approximately $58^{\circ} \mathrm{N}$, the water column was mixed down to the permanent thermocline, while higher values indicate a stratified water column (Ganssen and Kroon, 2000). Through the estimation of the strength of stratification, the intensity of the spring bloom can be deduced. Feldmeijer et al. (2015) estimate that during the glacial the ocean is well mixed, becoming stratified at the termination, before transitioning toward a well-mixed water column during the climate minima of MIS7d. Faunal and geochemical data between MIS9 and MIS7 suggest that a sharp temperature gradient existed between the North Atlantic Ocean $\left(55^{\circ} \mathrm{N}\right)$ and the Nordic Seas $\left(68-76^{\circ} \mathrm{N}\right)$ (Ruddiman and McIntyre, 1976; Ruddiman et al., 1986; Bauch, 1997), as a result of a relatively minor ingress of warm Atlantic surface water into the Nordic Sea. The deviation from an expected size decrease for both G. bulloides and $G$. inflata, due to a reduction in temperature at the glacial, may have been counterbalanced by a more productive water column.

\subsection{Depth habitat}

Planktonic foraminifera, as pelagic organisms, can be considered to have optimal conditions that are both geographic and vertical. The fact that the expected size decrease in relation to the geographic movement of the oceanic fronts appears to not occur could also have some relation to changes in depth habitat. The depth habitat of planktonic foraminifera has long been considered to relate to temperature (Emiliani, 1954), although later researchers would consider that it is the specific thermal structure of the water column, others have examined other properties including, but not limited to, stratification of the water column (McKenna and Prell, 2004); development of the thermocline; the depth and development of the chlorophyll maximum zone; food availability; and the depth of light penetration (Caron et al., 1981; Hemleben et al., 1989). Different ecological niches are associated with differences in the depth habitat. Spinose species, for example, are commonly associated with both a shallower depth habitat and symbionts that act as an important food source in oligotrophic conditions. Depth habitat reconstructions, calculated via species abundance counts in plankton tows and/or the isotopic analysis of foraminifera tests from the sediment, have placed the species analysed as distinct ecological niches associated with "shallow", "intermediate" and "deep" depths, for G. bulloides, G. inflata and G. truncatulinoides, respectively.

Hemleben and Spindler (1983) reported that the preferred depth habitat of $G$. bulloides is between the surface mixed layer and $200 \mathrm{~m}$. Both Bé (1977) and Deuser and Ross (1989), however, suggested a shallower depth habitat of 50-100 and 25-50 m, respectively. The species depth habitat appears strongly controlled by the distribution of particulate food. The deep chlorophyll maximum (DCM) is often associated with high(er) abundance of this species, and since the DCM may be found at different depths seasonally or due to water column structure (although predominately at the base of the surface mixed layer), one can expect this species to follow the food-rich levels in the water column. Seasonal variability in the depth habitat may account for this discrepancy between authors. Based upon plankton tow sampling, Ottens (1992) ascribed a greater depth $(0-100 \mathrm{~m})$ in April than in August $(0-50 \mathrm{~m})$. However, the non-spinose $G$. inflata is considered to be an intermediate- to deeper-dwelling species, typically associated with the base of the seasonal thermocline (Cléroux et al., 2007, 2008; Ganssen and Kroon, 2000; Groeneveld and Chiessi, 2011; Lončarić et al., 2006) associated with subpolar to subtropical water masses, which in the South Atlantic have been quantified to be between 13 and $19^{\circ} \mathrm{C}$ (Bé, 1969; Farmer et al., 2011; Ganssen and Sarnthein, 1983; Thiede, 1971, 1975). However, it has been shown to dominate the lower temperature $\left(2-6^{\circ} \mathrm{C}\right)$ subantarctic region in the South Pacific (Bé, 1969). Calcification, however, occurs from the mixed layer down to water depths of 500-800 m (Hemleben and Spindler, 1983; Wilke et al., 2006). Narrower depth intervals have been proposed for both the North Atlantic, at 0-150 m (Ottens, 1992) and 300-400 m (Elderfield and Ganssen, 2000), and the South Atlantic at 50-300 m (Mortyn and Charles, 2003). The nonspinose species $G$. truncatulinoides has a dimorphic coiling provincialism (dextral and sinistral), although it is considered to inhabit a deep depth, down to approximately $\sim 800 \mathrm{~m}$ or even deeper (Hemleben et al., 1985; Lohmann, 1992; Lohmann and Schweitzer, 1990), where they are considered to secrete a secondary "gametogenetic" crust (Bé and Ericson, 1963; Hemleben et al., 1985). Given the considerable depths that $G$. truncatulinoides inhabits, it likely feeds on detritus settling from the photic zone. Its morphology, more explicitly the height of the conical shell, has changed temporally and spatially (Lohmann, 1992, and references therein), with different populations having different isotopic compositions (Williams et al., 1988). Fairbanks et al. (1980) found, using plankton tows, that this species has enriched values of $\delta^{18} \mathrm{O}$, compared to equilibrium values, when found above the thermocline; that it is in equilibrium on the thermocline; and that is has depleted values of $\delta^{18} \mathrm{O}$ below it. This deviation is likely caused by offsets between primary and secondary crusts (McKenna and Prell, 2004; Mulitza et al., 1997; Vergnaud Grazzini, 1976), although this may be a seasonalencrusting artefact (Spear et al., 2011). Our results show that 
(A)
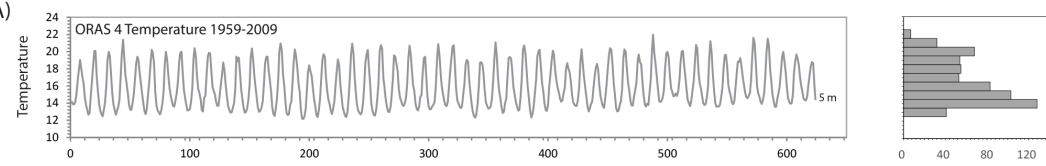

(B)
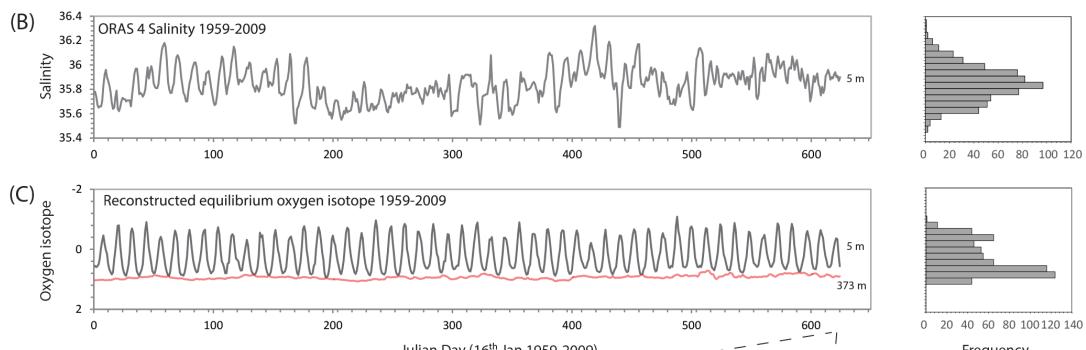

(D)

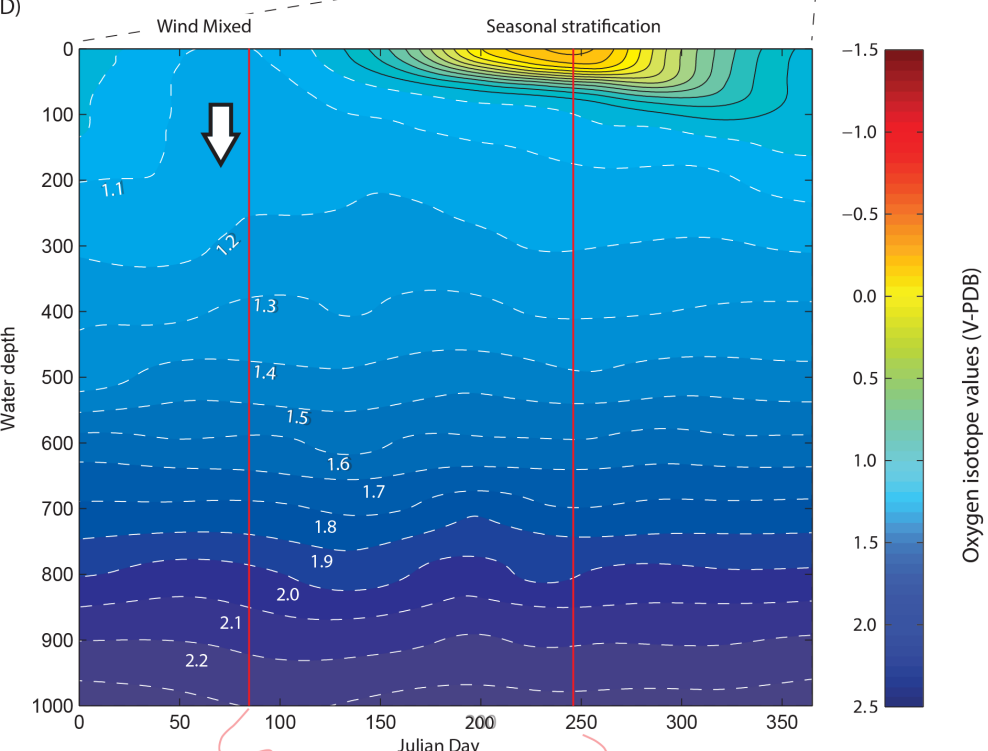

(E)

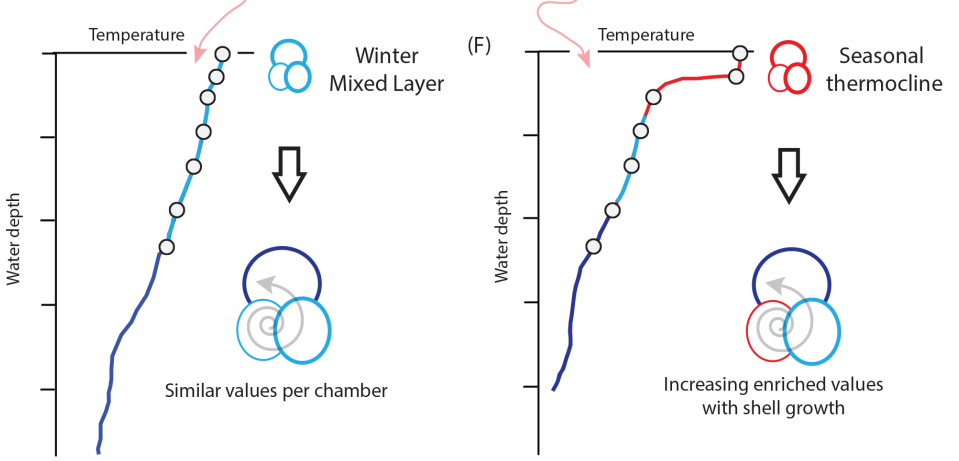

Figure 11. Schematic diagram of the key hydrological parameters at the core site and the insolation pattern for the studied interval. Ocean reanalysis data set of (a) monthly temperatures and (b) monthly salinity at $5 \mathrm{~m}$ water depth for the years 1959-2009, excluding the warming since 2009 (Balmaseda et al., 2013). Using (a) and (b), the (c) oxygen isotope equilibrium was calculated for $5 \mathrm{~m}$ (black line), for reference (red line). (d) Oxygen isotope equilibrium $\left(\delta^{18} \mathrm{O}_{\mathrm{eq}}\right)$ representing the water structure plotted against time based upon "an average year" using values of World Ocean Atlas (WOA09) extracted from Ocean Data View (ODV). The main foraminiferal flux, as determined by the North Atlantic Bloom Experiment (NABE), the initial pilot study of the Joint Global Ocean Flux Study (JGOFS), lies between March and July. Maximum insolation occurs in June; however, the warmest month is later in September/October. Estimated depth habitat of G. bulloides, G. inflata and G. truncatulinoides is 100, 400 and $800 \mathrm{~m}$, respectively. Schematically, foraminifera that calcify in the winter mixed layer (e) are likely to record similar values for each successive chamber in comparison with those foraminifera that calcify in the seasonal thermocline (f). 
species with a larger modern depth habitat, such as globorotalids, have for the most part a statistically significant offset between smaller- and larger-sized specimens in the sedimentary record. With increasing water depth, oxygen isotope equilibrium values become successively more enriched (Fig. 11); considering that size and depth are linked, our results parallel the work of Williams et al. (1981) and the later work of Lončarić et al. (2006) in suggesting that the $\delta^{18} \mathrm{O}$ of smaller-sized (predominately globorotalid) foraminifera record upper ocean/surface conditions. During the descent through the water column foraminifera add new calcite; their shells' geochemical composition is therefore an integrated history of the hydrology at different water depths (Hemleben and Bijma, 1994; Wilke et al., 2006) (Fig. 11).

\subsection{Seasonality}

The isotopic composition of larger specimens represents continuous calcification through the water column to deeper waters with lower temperatures, thus giving enriched values in $\delta^{18} \mathrm{O}$. Given the isotopic overlap of the $>250 \mu \mathrm{m}$ in all species, it is possible that no size-depth stratification occurs after a given growth stage. However, given that the seasonal temperature variation with depth is small $\left(<1^{\circ} \mathrm{C}\right.$ for $200 \mathrm{~m}$, $<0.6^{\circ} \mathrm{C}$ for $500 \mathrm{~m}$ ), different sizes may represent growth in different seasons with varying ecological constraints. However, the "mixed" signal, for instance at $214.5 \mathrm{ka}$ for $G$. bulloides, where both small and large specimens have the same $\delta^{18} \mathrm{O}$, would suggest a seasonal effect. The modern seasonal temperature range at the core site is $10-12^{\circ} \mathrm{C}$; assuming that a change of $1 \%$ corresponds to a $4{ }^{\circ} \mathrm{C}$, the amplitude of the seasonal temperature signal alone is approximately $2.5-3.0 \%$. This is further complicated by potential changes attributable to evaporation and precipitation and the occasional-intermittent presence of freshwater pulses, as the core site is situated within the ice-rafted debris (IRD) belt (Hodell and Curtis, 2008). If we consider that the isotope values of $250-355 \mu \mathrm{m}$ occur during favourable conditions, the two end members (212-250 and 355-400 $\mu \mathrm{m})$ could occur during unfavourable conditions during the height of summer, when the water column is strongly stratified. Curiously, the average correlation coefficient between $\delta^{18} \mathrm{O}$ and $\delta^{13} \mathrm{C}$ shows a reversal in its decrease with size trend in this larger size fraction $(355-400 \mu \mathrm{m})$ which may support this seasonal explanation, although it may also be a change in vital effect or metabolic dominance of the isotopic signal.

Intriguingly, there are a number of instances where the smallest specimens of $G$. inflata have similar values to larger specimens $(>250 \mu \mathrm{m})$ - these events occurring halfway between insolation minima and maxima, apart from at 234$239 \mathrm{kyr}$ BP during the onset of the termination. Were this offset to be the result of a shoaling of the depth habitat, then larger specimens would be expected to show similar values to smaller specimens and not the other way around. The fact that these $\delta^{18} \mathrm{O}$ values measured of $G$. inflata show a relation-

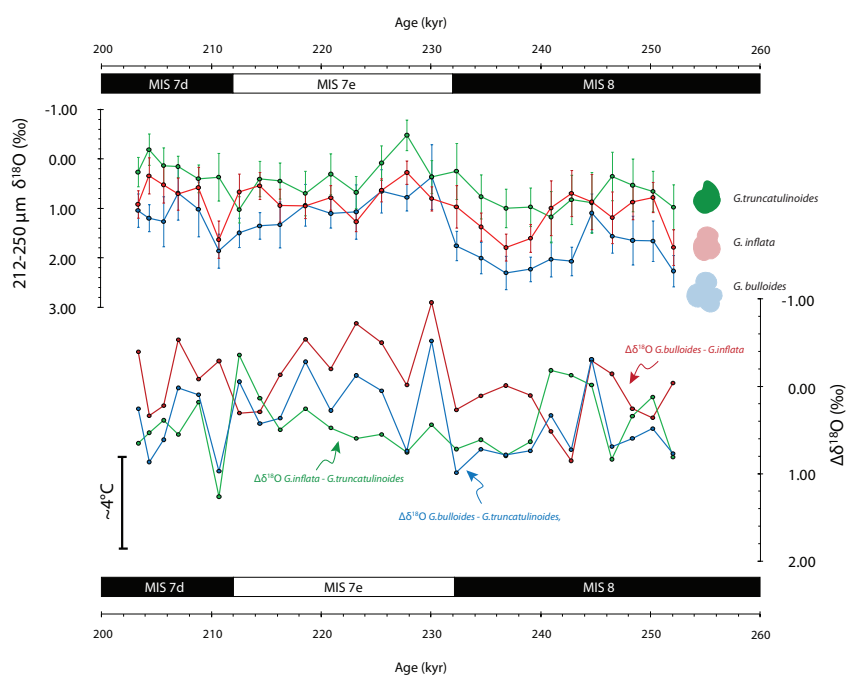

Figure 12. Oxygen isotope of smallest size fraction and differences. (a) The oxygen isotopes between small-sized specimens of $G$. bulloides, G. inflata and G. truncatulinoides and (b) the calculated difference between species $\left(\Delta \delta^{18} \mathrm{O}\right)$.

ship with $\delta^{18} \mathrm{O}_{355-400 \mu \mathrm{m}}$ G. bulloides $(r=0.7025 ; n=8)$ suggests a modification of the structure of the upper ocean. The biological vertical structure of the water column is dependent upon the amount of incidental light, notwithstanding surface ocean processes such as surface layer mixing (Fig. 11d-f). In the modern ocean the average wind velocity increases between November and February, which mixes the ocean down to depths of 150-300 m (Broerse et al., 2000). The penetrative depth of sunlight, and thus the surface available to direct heating, is greater in the ocean $(\sim 100 \mathrm{~m})$ than on land $(\sim 1-2 \mathrm{~m})$; accordingly, temperature change in the ocean is distributed over a larger area than on land, which has a lower capacity to either conduct or store heat. Variation in the ocean-land heat contrast directly affects the influence of wind strength in the region and thus the strength of winddriven turbulence that the mixes the upper ocean. The fact that these events occur halfway between a minima and maxima in insolation may suggest that the wind regime over this region of the North Atlantic is particularly sensitive to the reduction in extremes. Likewise, the shift in both the relative abundance (Fig. 3) and the oxygen isotopic standard deviation (Fig. S7) of G. bulloides corresponds to a change in the insolation difference between the vernal equinox and the summer solstice (e.g. between March and June) $(r=0.5748$; $n=26$ ). This means that, when the difference between the two seasons is greatest, the growing season is reduced, and thus the surface species has a "reduced" range of values. It is postulated that, during periods of reduced seasonality, the stratification that exists in the summer months was not as strong as it is today. 


\section{5 $\Delta \delta^{18} \mathrm{O}$ between species}

Oxygen isotopes between similar sizes of different species show differences between small specimens $(212-250 \mu \mathrm{m})$ of the deep-dwelling $G$. truncatulinoides and the surfacedwelling G. bulloides of up to $1.3 \% \circ \Delta \delta^{18} \mathrm{O}$ (corresponding to $\sim 5^{\circ} \mathrm{C}$ ) during some periods, although on average this offset is smaller at $\sim 0.5 \%$ or $2^{\circ} \mathrm{C}$ (Fig. 12). This pattern can be accomplished by (1) differences in $\delta^{18} \mathrm{O}$ fractionation factors between species confirmed by numerous authors (Curry and Matthews 1981; Duplessy et al., 1981; Fairbanks et al., 1980; Shackleton, 1974; Shackleton et al.,1973; Vergnaud-Grazzini, 1976; Williams et al., 1979), (2) calcification in a water mass with a different ambient $\delta^{18} \mathrm{O}_{\text {eq }}$, i.e. convection and sinking of isotopically depleted water (Macdonald et al., 1995) during sea ice formation (Rohling and Bigg, 1998; Strain and Tan, 1993), (3) expatriation of more southerly grown specimens via a proto-Gulf Stream deflected by a southerly polar front (Cifelli and Smith, 1970; Lototskaya and Ganssen, 1999; Phleger et al., 1953; Weyl, 1978) or (4) calcification in distinct seasons. Explanation 2, that calcification occurs in a water mass with a different $\delta^{18} \mathrm{O}_{\mathrm{sw}}$, is plausible. For instance, during sea ice formation, surrounding water masses become isotopically depleted as the $\delta^{18} \mathrm{O}$ of sea ice is $2.57 \pm 0.10 \%$ enriched relative to the isotopic composition of sea water (Macdonald et al., 1995), the formation of which increases surface ocean salinity enough to lead to convection and sinking of this depleted water mass (Rohling and Bigg, 1998; Strain and Tan, 1993). This depleted water mass is replaced by surface waters (to some degree) unaffected by the freezing process (Rohling and Bigg, 1998), meaning that species that calcify during sea ice formation will have depleted $\delta^{18} \mathrm{O}$ values. Similarly, the core site is situated within the IRD belt (Hodell and Curtis, 2008; Park, 1998), indicating that this area would have been affected by meltwater during certain periods of the year. However, both of these hypotheses cannot satisfactorily explain the continuation of this phenomena in shallower "interglacial" depths of the core.

Explanation 3 finds support from observations of Phleger et al. (1953) that low-latitude faunas are circulated northwards in the western portion of the Atlantic Basin, whereas high-latitude faunas are displaced southwards in the eastern basin, as dictated by the clockwise direction of the currents within the North Atlantic gyre (Fig. 1). The large difference between the fine fractions of G. bulloides and G. truncatulinoides (up to $1.3 \%$ ) cannot account for differences in calcification depth alone, as it would indicate a deeper calcification for G. bulloides. Instead calcification at a more southerly and warmer location is plausible. During glacial conditions the biogeographic distribution of this species contracts to lower latitudes as the boundary of the polar front moves southwards down to the latitude of the Iberian margin. Expatriates carried by the proto-Gulf Stream would have been deflected along the polar front (Lototskaya and Ganssen, 1999; Weyl,
1978) into this core location as deduced by the IRD belt (Berger and Jansen, 1995; Ruddiman and McIntyre, 1981). Cifelli and Smith (1970), through releasing drift bodies from eastern North America, indicated that surface currents could redistribute organisms when they collected these same drift bodies in the Azores. It is possible that the specimens with more depleted $\delta^{18} \mathrm{O}$ values represent the endemic population, and that the more enriched specimens are expatriates (Lototskaya and Ganssen, 1998). Had these expatriates emigrated into unfavourable conditions, they may not have grown additional chambers in equilibrium with the ambient conditions and thus an observable offset would have occurred.

Both explanation 2 and 3 can be discounted given that the phenomenon occurs irrespective of oceanic mode (i.e. glacial-interglacial). Given the seasonal flux (Tolderlund and Bé, 1971), this isotopic difference could relate to deep-sea sediments being composed of specimens from species that potentially calcify during different seasons (Williams et al., 1979), therefore requiring no problematic large-scale transport. Tolderlund and Bé (1971), based upon 4 years of seasonally collected plankton tows at weather station Ocean Station Delta $\left(44^{\circ} 00^{\prime} \mathrm{N}, 41^{\circ} 00^{\prime} \mathrm{W}\right)$, considered that $G$. bulloides had a continuous flux throughout the period of November to August, while both $G$. inflata and $G$. truncatulinoides each show two flux maxima. This relates to temperatures during this time window of between 10 and $23^{\circ} \mathrm{C}$ for $G$. bulloides, between 10 and $23{ }^{\circ} \mathrm{C}$ for $G$. inflata, and between 8 and $22^{\circ} \mathrm{C}$ for $G$. truncatulinoides. Whilst these temperature distributions suggest that $G$. truncatulinoides occurs in colder waters, the optimum temperatures of these species are 10 $12^{\circ} \mathrm{C}, 10-17$ and $15-18^{\circ} \mathrm{C}$, respectively, consistent with the idea of calcification in warmer temperatures (Tolderlund and Bé, 1971). Globigerina bulloides has highest fluxes during the spring bloom prior to stratification of the water column; were $G$. truncatulinoides to calcify later in the year, at the base of the thermocline, it would explain the deviation in isotopic composition between the two species.

\subsection{Carbon isotopes}

In comparison with oxygen isotopes there is generally an enrichment in ${ }^{13} \mathrm{C}$ with size, synonymous with previous studies (Franco-Fraguas et al., 2011; Fridrich et al., 2012; Birch et al., 2013), as per the "normal" trend (Berger et al., 1978). The $\delta^{13} \mathrm{C}$ of planktonic foraminifera has been linked to photosymbionts through changes in the microenvironment (Spero and DeNiro, 1987); metabolic fractionation, i.e. respiration (Berger et al., 1978); diet (DeNiro and Epstein, 1978); and metabolic and/or symbiotic influences on the ambient and internal carbon pool (i.e. carbonate ion concentration). It is self-evident that the same depth related size- $\delta^{18} \mathrm{O}$ trends are not applicable to carbon isotopes. In contrast to the $\delta^{18} \mathrm{O}$ equilibrium values, the vertical structure of the $\delta^{13} \mathrm{C}$ of dissolved inorganic carbon (DIC $\equiv \sum \mathrm{CO}_{2}$ ) is a consequence of the surface photosynthesis and the oxidation of organic 
matter at depth. The isotopic composition of DIC therefore varies vertically, resulting in depleted $\delta^{13} \mathrm{C}$ values at depth as opposed to the enrichment seen in $\delta^{18} \mathrm{O}$. As photosynthesis preferentially favours uptake of ${ }^{12} \mathrm{C}$, organic matter produced through this pathway has typical $\delta^{13} \mathrm{C}$ values of between -20 and $-25 \%$; as a result the DIC at the surface, in the photic zone, is enriched in $\delta^{13} \mathrm{C}$ by approximately $\sim 2 \%$. As the isotopically depleted organic matter sinks, it is oxidised, lowering the ambient $\delta^{13} \mathrm{C}$ value to approximately $\sim 0 \%$. The calcification depth surmised from using only $\delta^{13} \mathrm{C}$, when compared with the modern $\delta^{13} \mathrm{C}_{\text {DIC }}$ vertical profile, would indicate a shallower depth habitat than that indicated by $\delta^{18} \mathrm{O}$ (see Feldmeijer et al., 2015).

Our results, however, show that the relative enrichment in $\delta^{13} \mathrm{C}$ between species is consistent with the depth habitat per se, i.e. deeper dwellers are more enriched than shallower dwellers (Fig. 9d). This discrepancy could relate to a (i) temperature-related fractionation, (ii) diet and/or (iii) the addition of a secondary crust. Species-specific temperaturedependent fractionation is likely caused by the influence of temperature on the physiological rates of the organism; for instance, a number of authors have demonstrated that, over small temperature ranges, the metabolic rate increases exponentially (Bijma et al., 1990; Ortiz et al., 1996). The change in $\delta^{13} \mathrm{C}$ per degree Celcius for G. bulloides has been estimated experimentally as $-0.11 \% 0^{\circ} \mathrm{C}^{-1}$, whereas for the symbiotic species Orbulina universa it is $2-3$ times less in the opposite direction, 0 to $+0.05 \%{ }^{\circ} \mathrm{C}^{-1}$ (Bemis et al., 2000). It is worth pointing out that, for the non-symbiotic species $G$. bulloides, this temperature effect will diminish the effect of higher glacial $\left[\mathrm{CO}_{3}^{2-}\right]$ (Bemis et al., 2000). Spero et al. (1997) through culturing experiments in which G. bulloides was grown at constant DIC showed that there is a strong dependence, $-0.012 \% /\left(\mu \mathrm{mol} \mathrm{kg}{ }^{-1}\right)$ on $\delta^{13} \mathrm{C}$, with $\left[\mathrm{CO}_{3}^{2-}\right]$. This strong dependence, a consequence of both kinetic and metabolic fractionation factors (Bijma et al., 1999), is species-specific (Peeters et al., 2002; Wilke et al., 2006). In the natural environment, the $\left[\mathrm{CO}_{3}^{2-}\right]$ varies regionally as the solubility of $\mathrm{CO}_{2}$ is temperature-dependent and vertically as organic matter is remineralised and the subsequent $\mathrm{CO}_{2}$ is released and hydrolysed. A $0.5 p \mathrm{H}$ decrease at the shallow oxygen minimum zone, for instance, would account for a $1 \%$ enrichment in $\delta^{13} \mathrm{C}$ for those species that inhabit it (Birch et al., 2013). This sinking organic matter may also contribute to changes in the $\delta^{13} \mathrm{C}$ of shell calcite through changes in food source, feeding efficiency and diet. DeNiro and Epstein (1978) highlighted, for instance, the fact that consumers are slightly enriched in $\delta^{13} \mathrm{C}$ from the composition of their food, with each trophic level raising their $\delta^{13} \mathrm{C}$ values - a process termed cumulative fractionation by McConnaughey and McRoy (1979a, b). Therefore carnivorous foraminifera are likely to have more enriched values in $\delta^{13} \mathrm{C}$ than herbivorous foraminifera. Likewise, Hemleben and Bijma (1994) suggested that dietary change between juveniles grazing on phytoplankton or feeding on detritus and the car- nivorous diet of later neanic and/or adult stages should coincide with an increase in $\delta^{13} \mathrm{C}$. Growth rate, final size, $\delta^{13} \mathrm{C}$ and rate of chamber addition have all been shown to correlate positively with increased feeding rate (Bé et al., 1981; Bijma et al., 1992; Hemleben et al., 1987; Ortiz et al., 1996), i.e. a doubling in feeding rate resulted in a decrease in $\delta^{13} \mathrm{C}$ by $1 \%$ for specimens of the symbiont-bearing Globigerinella siphonifera (Hemleben and Bijma, 1994). Younger (or smaller) foraminifera are inferred to have higher respiration rates (high metabolic rate and thus increased kinetic fractionation), which during calcification leads to a greater amount of metabolic $\mathrm{CO}_{2}$ depleted in ${ }^{13} \mathrm{C}$ incorporated into shell calcite (Bemis et al., 2000; Berger et al., 1978; Ravelo and Fairbanks, 1995). As metabolic rates slow with growth, the shell becomes more isotopically enriched as the incorporation of light carbon decreases (Bemis et al., 2000; Berger et al., 1978; Birch et al., 2013; Fairbanks et al., 1982; Oppo and Fairbanks, 1989; Spero and Lea, 1996; Vincent and Berger, 1981). The addition of a secondary crust, or gametogenetic calcite, at depth, potentially via absorption and remineralisation of earlier chambers and spines during preparations for reproduction, may lead to an isotopic offset (Hemleben et al., 1989; Schiebel and Hemleben, 1995). When restricted to measuring only primary calcite, Lohmann (1995) found that there was no size- $-{ }^{13} \mathrm{C}$ trend; however, as noted by Birch et al. (2013) this mechanism would result in depleted values not the enriched values observed.

The transition between a glacial and interglacial further exacerbates interpretation of carbon isotope trends. Bemis et al. (2000) suggested that the $\delta^{13} \mathrm{C}$ of DIC of the surface ocean during the glacial would have to increase by 0.3 to $0.4 \%$ o to account for changes in sea surface temperature and alkalinity. A similar figure was estimated by Broecker and Henderson (1998), at $0.35 \%$, although they considered that it should be in response to an enhanced biological pump drawing down $\mathrm{CO}_{2}$. A conservative estimate, given the poorly constrained alkalinity inventory, of $60 \mu \mathrm{mol} \mathrm{kg}^{-1}$ change in $\left[\mathrm{CO}_{3}^{2-}\right]$ at the Last Glacial Maximum would have decreased the $\delta^{13} \mathrm{C}$ of G. bulloides by $0.72 \%$. Given that the $p \mathrm{CO}_{2}$ of MIS8 never reaches the lower boundary of $180 \mathrm{ppm}$, it is likely that this value is lower for the period of study. Irrespective of whether $\mathrm{CO}_{2}$ or temperature changed first, unravelling the dominant influence on shell $\delta^{13} \mathrm{C}$ is problematic. If, for instance, a species altered its season of calcification so that during glacial periods it calcified in warmer months and during interglacials in colder months, then this temperature influence could be negated. Regardless, this problem is further complicated by the fact that, as shown by our data, the use of $\delta^{18} \mathrm{O}$ to estimate calcification depth leads to the specimens not fitting the $\delta^{13} \mathrm{C}$ profiles. Shackleton (1978) pointed out that trying to estimate the carbon isotope composition of the surface ocean is particularly tenuous, given that the gradient in carbon isotope values is steepest at the surface when 
coupled with the limitations and uncertainties regarding the precise depth of calcification.

\section{Conclusions}

Oxygen isotopic analysis of specimens from different size fractions reveal that, for globorotalids, smaller shells are isotopically depleted compared to larger shells, whilst we find no systematic differences between the $\delta^{18} \mathrm{O}$ of $G$. bulloides in different size fractions. The depletion for globorotalid species is inferred to be an effect of different depths inhabited during ontogeny, with smaller specimens calcifying in the warmer shallower surface waters prior to migrating to depth. A large offset between small and larger specimens of $G$. truncatulinoides can be explained by calcification during a warmer season at a shallower water depth. Carbon isotopes show a greater degree of variability, which is inferred to relate to changes in metabolism. Differences between size fractions appear not to be constant temporally or even spatially, as shown by the difference between the data presented here and those previously published. This is likely the reason for the lack of a resolution in the existing literature as to the recommended size fraction for isotopic analysis. Our results would suggest that $300-355 \mu \mathrm{m}$ serves this purpose given the offsets between the species; however we would caution against using a "one-size-fits-all" approach given the seasonal structure of the water column and seasonal succession of species at this core location. Further studies are needed to understand how this size-isotope relationship varies in regions with reduced seasonality, more/less stable and unstable water column dynamics and during transient events, for example associated with sapropel layers.

\section{The Supplement related to this article is available online at doi:10.5194/bg-12-4781-2015-supplement.}

Acknowledgements. The authors would like to thank the two anonymous reviewers and the editor for their contributions that helped to improve the manuscript. This paper is a contribution to the European 7th Framework Programme project EPOCA (European Project for Ocean Acidification; FP7/211384), the Darwin Center for Biogeosciences Project 3040 "Sensing Seasonality" and the NWO-funded project "Digging for density" (NWO/822.01.0.19). Financial assistance was also provided to the lead author by the VU University Amsterdam. Piston core T90-9p was taken during a joint JGOFS-APNAP expedition aboard the R/V Tyro funded by the Nederlandse Organisatie voor Wetenschappelijk Onderzoek (NWO).

Edited by: J. Bijma

\section{References}

Balmaseda, M. A., Mogensen, K., and Weaver, A. T.: Evaluation of the ECMWF ocean reanalysis system ORAS4, Quarterly J. Roy. Meteorol. Soc., 139, 1132-1161, 2013.

Bard, E.: Paleoceanographic implications of the difference in deepsea sediment mixing between large and fine particles, Paleoceanography, 16, 235-239, 2001.

Bard, E., Arnold, M., Duprat, J., Moyes, J., and Duplessy, J.-C.: Reconstruction of the last deglaciation: deconvolved records of $\delta^{18} \mathrm{O}$ profiles, micropaleontological variations and accelerator mass spectrometric ${ }^{14} \mathrm{C}$ dating, Clim. Dynam., 1, 101-112, 1987.

Bauch, H. A.: Paleoceanography of the North Atlantic Ocean $\left(68-76^{\circ} \mathrm{N}\right)$ during the past $450 \mathrm{ky}$ deduced from planktic foraminiferal assemblages and stable isotopes, Contribut. Micropaleontol. Paleoceanogr. North. North Atlantic, 5, 83-100, 1997.

Bé, A. W. H.: Planktonic Foraminifera, in: Distribution of Selected Groups of Marine Invertebrates in Waters South of $35^{\circ} \mathrm{S}$ latitude, Antarctic Map Folio Series, Am. Geograph. Soc., 1969.

Bé, A. W. H.: An ecological, zoogeographic, and taxonomic review of recent Planktonic Foraminifera, in: Oceanic Micropalaeontology, edited by: Ramsay, A. T. S., Academic Press, London, 1100, 1977.

Bé, A. W. H. and Ericson, D. B.: Aspects of calcification in planktonic foraminifera (Sarcodina)* , Ann. New York Acad. Sci., 109, 65-81, 1963.

Bé, A. W. H. and Lott, L.: Shell growth and structure of planktonic foraminifera, Science, 145, 823-824, 1964.

Bé, A. W. H. and Tolderlund, D. S.: Distribution and ecology of living planktonic foraminifera in surface waters of the Atlantic and Indian Oceans, in: Micropaleontology of Oceans, edited by: Funnell, B. M. and Riedel, W. R., Cambridge University Press, London, 105-149, 1971.

Bé, A. W. H., McIntyre, A., and Breger, D. L.: Shell Microstructure of a Planktonic Foraminifer, Globorotalia menardii (d'Orbigny), Eclogae geologicae Helvetiae, 59, 885-896, 1966.

Bé, A. W. H., Harrison, S. M., and Lott, L.: Orbulina universa d'Orbigny in the Indian Ocean, Micropaleontology, 19, 150-192 1973.

Bé, A. W. H., Hemleben, C., Anderson, O. R., Spindler, M., Hacunda, J., and Tuntivate-Choy, S.: Laboratory and field observations of living planktonic foraminifera, Micropaleontology, 23, 155-179, 1977.

Bé, A. W. H., Caron, D. A., and Anderson, O. R.: Effects of feeding frequency on life processes of the planktonic foraminifer Globigerinoides sacculifer in laboratory culture, J. Mar. Biol. Assoc. UK, 61, 257-277, 1981.

Bemis, B. E., Spero, H. J., Lea, D. W., and Bijma, J.: Temperature influence on the carbon isotopic composition of Globigerina bulloides and Orbulina universa (planktonic foraminifera), Mar. Micropaleontol., 38, 213-228, 2000.

Berger, A., Loutre, M. F., and Mélice, J. L.: Equatorial insolation: from precession harmonics to eccentricity frequencies, Clim. Past, 2, 131-136, doi:10.5194/cp-2-131-2006, 2006.

Berger, W. H.: Ecologic patterns of living planktonic Foraminifera, Deep-Sea Res. Oceanogr. Abstr., 16, 1-24, 1969.

Berger, W. H.: Sedimentation of planktonic foraminifera, Mar. Geol., 11, 325-358, 1971. 
Berger, W. H.: Preservation of foraminifera, Houston, 105-155, 1979.

Berger, W. H. and Jansen, E.: Younger Dryas episode: ice collapse and super fjord heat pump, in: The Younger Dryas, edited by: Troelstra, S. R., Van Hinte, J. E., and Ganssen, G. M., Koninklijke Nederlandse Akademie van Wetenschappen verhandelingen, Afd. Natuurkunde, 1, Koninklijke Nederlandse Akademie van Wetenschappen, Amsterdam, 1995.

Berger, W. H., Diesterhaass, L., and Killingley, J. S.: Upwelling off northwest africa-holocene decrease as seen in carbon isotopes and sedimentological indicators, Oceanol. Acta, 1, 3-7, 1978a.

Berger, W. H., Killingley, J. S., and Vincent, E.: Stable isotopes in deep-sea carbonates: Box Core ERDC-92, west equatorial Pacific, Oceanol. Acta, 1, 203-216, 1978 b.

Bijma, J., Faber, W. W., and Hemleben, C.: Temperature and salinity limits for growth and survival of some planktonic foraminifers in laboratory cultures, J. Foramin. Res., 20, 95-116, 1990.

Bijma, J., Hemleben, C., Oberhaensli, H., and Spindler, M.: The effects of increased water fertility on tropical spinose planktonic foraminifers in laboratory cultures, J. Foramin. Res., 22, 242256, 1992.

Bijma, J., Spero, H. J., and Lea, D. W.: Reassessing foraminiferal stable isotope geochemistry: Impacts of the oceanic carbonate system (Experimental results), in: Use of Proxies in Paleoceanography: Examples from the South Atlantic, edited by: Fischer, G. and Wefer, G., Springer-Verlag, Berlin Heidelberg, 489512, 1999.

Billups, K. and Spero, H. J.: Relationship between shell size, thickness and stable isotopes in individual planktonic foraminifera from two equatorial Atlantic cores, J. Foramin. Res., 25, 24-37, 1995.

Birch, H., Coxall, H. K., Pearson, P. N., Kroon, D., and O'Regan, M.: Planktonic foraminifera stable isotopes and water column structure: Disentangling ecological signals, Mar. Micropaleontol., 101, 127-145, doi:10.1016/j.marmicro.2013.02.002, 2013.

Bonneau, M.-C., Vergnaud-Grazzini, C., and Berger, W. H.: Stable isotope fractionation and differential dissolution in recent planktonic foraminifera from Pacific box-cores, Oceanol. Acta, 3, 377-382, 1980.

Bouvier-Soumagnac, Y. and Duplessy, Y.: Carbon and oxygen isotopic composition of planktonic foraminifera from laboratory culture, plankton tows and recent sediment: implications for the reconstruction of paleoclimatic conditions and of the global carbon cycle, J. Foramin. Res., 15, 302-320, 1985.

Broecker, W. S. and Henderson, G. M.: The sequence of events surrounding Termination II and their implications for the cause of glacial-interglacial $\mathrm{CO}_{2}$ changes, Paleoceanography, 13, 352364, 1998

Broerse, A. T. C., Ziveri, P., Van Hinte, J. E., and Honjo, S.: Coccolithophore export production, species composition, and coccolith$\mathrm{CaCO}_{3}$ fluxes in the NE Atlantic $\left(34^{\circ} \mathrm{N}, 21^{\circ} \mathrm{W}\right.$ and $48^{\circ} \mathrm{N}$, $\left.21^{\circ} \mathrm{W}\right)$, Deep-Sea Res. Pt. II, 47, 1877-1906, 2000.

Brummer, G.-J. A., Hemleben, C., and Spindler, M.: Planktonic foraminiferal ontogeny and new perspectives for micropalaeontology, Nature Publishing Group, 1986.

Brummer, G.-J. A., Hemleben, C., and Spindler, M.: Ontogeny of extant spinose planktonic foraminifera (Globigerinidae): A concept exemplified by Globigerinoides sacculifer (Brady) and G. ruber (d'Orbigny), Mar. Micropaleontol., 12, 357-381, 1987.
Caron, D. A., Bé, A. W. H., and O. R., A.: Effects of variations in light intensity on life processes of the planktonic foraminifera Globigerinoides sacculifer in laboratory culture, J. Mar. Biol. Assoc. UK, 62, 435-451, 1981.

Cifelli, R. and Smith, R. K.: Distribution of Planktonic Foraminifera in the Vicinity of the North Atlantic Current, Smithsonian Contributions to Paleobiology, 4, p. 51, 1970.

Cléroux, C., Cortijo, E., Duplessy, J.-C., and Zahn, R.: Deep-dwelling foraminifera as thermocline temperature recorders, Geochem., Geophys. Geosys., 8, Q04N11, doi:10.1029/2006GC001474, 2007.

Cléroux, C., Cortijo, E., Anand, P., Labeyrie, L., Bassinot, F., Caillon, N., and Duplessy, J.-C.: $\mathrm{Mg} / \mathrm{Ca}$ and $\mathrm{Sr} / \mathrm{Ca}$ ratios in planktonic foraminifera: Proxies for upper water column temperature reconstruction, Paleoceanography, 23, PA3214, doi:10.1029/2007PA001505, 2008.

Curry, W. B. and Matthews, R.: Equilibrium ${ }^{18} \mathrm{O}$ fractionation in small size fraction planktonic foraminifera:evidence from recent Indian Ocean sediments, Mar. Micropaleontol., 6, 327-337, 1981.

DeNiro, M. J. and Epstein, S.: Influence of diet on the distribution of carbon isotopes in animals, Geochim. Cosmochim. Acta, 42, 495-506, 1978.

Deuser, W. G. and Ross, E. H.: Seasonally abundant planktonic foraminifera of the Sargasso Sea: Succession, deep-water fluxes, isotopic compositions, and paleoceanographic implications, J. Foramin. Res., 19, 268-293, 1989.

de Villiers, S.: Optimum growth conditions as opposed to calcite saturation as a control on the calcification rate and shell-weight of marine foraminifera, Mar. Biol., 144, 45-49, 2004.

Duplessy, J. C., Bé, A. W. H., and Blanc, P. L.: Oxygen and carbon isotopic composition and biogeographic distribution of planktonic foraminifera in the Indian Ocean, Palaeogeogr. Palaeoclimatol. Palaeoecol., 33, 9-46, 1981.

Elderfield, H. and Ganssen, G. M.: Past temperature and $\delta^{18} \mathrm{O}$ of surface ocean waters inferred from foraminiferal $\mathrm{Mg} / \mathrm{Ca}$ ratios, Nature, 405, 442-445, 2000.

Elderfield, H., Vautravers, M., and Cooper, M.: The relationship between shell size and $\mathrm{Mg} / \mathrm{Ca}, \mathrm{Sr} / \mathrm{Ca},{ }^{18} \mathrm{O}$, and ${ }^{13} \mathrm{C}$ of species of planktonic foraminifera, Geochem. Geophys. Geosys., 3, 1-13, 2002.

Emiliani, C.: Depth habitats of some species of pelagic foraminifera as indicated by oxygen isotope ratios, Am. J. Sci., 252, 149-158, 1954.

Emiliani, C.: Pleistocene Temperatures, J. Geol., 63, 538-578, 1955.

Emiliani, C.: Isotopic paleotemperatures and shell morphology of Globigerinoides rubra in the type section of the PliocenePleistocene boundary, Micropaleontology, 17, 233-237, 1971.

Fairbanks, R. G., Wiebe, P. H., and Bé, A. W. H.: Vertical distribution and Isotopic Composition of Living Planktonic Foraminifera in the Western North Atlantic, Science, 207, 61-63, 1980.

Fairbanks, R. G., Sverdlove, M., Free, R., Wiebe, P. H., and Bé, A. W. H.: Vertical distribution and isotopic fractionation of living planktonic foraminifera from the Panama Basin, Nature, 298, 841-844, 1982.

Farmer, E. J., Chapman, M. R., and Andrews, J. E.: Holocene temperature evolution of the subpolar North Atlantic recorded in the 
$\mathrm{Mg} / \mathrm{Ca}$ ratios of surface and thermocline dwelling planktonic foraminifers, Glob. Planet. Change, 79, 234-243, 2011.

Feldmeijer, W., Metcalfe, B., Brummer, G. J. A., and Ganssen, G. M.: Reconstructing the depth of the permanent thermocline through the morphology and geochemistry of the deep dwelling planktonic foraminifer Globorotalia truncatulinoides, Paleoceanography, 30, PA002687, doi:10.1002/2014PA002687, 2015.

Franco-Fraguas, P., Costa, K. B., and Toledo, F. A. L.: Relationship between isotopic composition $\left(\Delta^{18} \mathrm{O}\right.$ and $\left.\Delta^{13} \mathrm{C}\right)$ and plaktonic foraminifera test size in core tops from the Brazilian Continental Margin, Braz. J. Oceanogr., 59, 327-338, 2011.

Friedrich, O., Schiebel, R., Wilson, P. A., Weldeab, S., Beer, C. J., Cooper, M. J., and Fiebig, J.: Influence of test size, water depth, and ecology on $\mathrm{Mg} / \mathrm{Ca}, \mathrm{Sr} / \mathrm{Ca}, \delta^{18} \mathrm{O}$ and $\delta^{13} \mathrm{C}$ in nine modern species of planktic foraminifers, Earth Planet. Sci. Lett., 319/320, 133-145, 2012.

Ganssen, G. M. and Kroon, D.: The isotopic signature of planktonic foraminifera from NE Atlantic surface sediments: implications for the reconstruction of past oceanic conditions, J. Geol. Soc., $157,693-699,2000$.

Ganssen, G. M. and Sarnthein, M.: Stable-isotope composition of foraminifers: the surface and bottom water record of coastal upwelling. In: Coastal Upwelling Its Sediment Record, Springer, 1983.

Ganssen, G. M., Peeters, F. J. C., Metcalfe, B., Anand, P., Jung, S. J. A., Kroon, D., and Brummer, G.-J. A.: Quantifying sea surface temperature ranges of the Arabian Sea for the past 20000 years, Clim. Past, 7, 1337-1349, doi:10.5194/cp-7-1337-2011, 2011.

Groeneveld, J. and Chiessi, C. M.: Mg/Ca of Globorotalia inflata as a recorder of permanent thermocline temperatures in the South Atlantic, Paleoceanography, 26, PA2203, doi:10.1029/2010PA001940, 2011.

Hammer, Ø., Harper, D. A. T., and Ryan, P. D.: PAST: Paleontological Statistics software package for education and data analysis, Palaeontol. Electron., 4, 1-9, 2001.

Hecht, A. D.: The oxygen isotopic record of foraminifera in deepsea sediment, Foraminifera, Academic Press, London, 1-43, 1974.

Hecht, A. D., Bé, A. W. H., and Lott, L.: Ecologic and paleoclimatic implications of morphologic variation of Orbulina universa in the Indian Ocean, Science, 194, 422-424, 1976.

Hemleben, C. and Bijma, J.: Foraminiferal population dynamics and stable carbon isotopes, in: Carbon Cycling in the Glacial Ocean: Constraints on the Ocean's Role in Global Change, Springer, 1994.

Hemleben, C. and Spindler, M.: Recent advances in research on living planktonic foraminifera, in: Reconstruction of marine Paleoenvironments, edited by: Meulenkamp, J. E., Utrecht Micropaleontological Bulletins, 141-170, 1983.

Hemleben, C., Spindler, M., Breitinger, I., and Deuser, W. G.: Field and laboratory studies on the ontogeny and ecology of some globorotaliid species from the Sargasso Sea off Bermuda, The J. Foramin. Res., 15, 254-272, 1985.

Hemleben, C., Spindler, M., Breitinger, I., and Ott, R.: Morphological and physiological responses of Globigerinoides sacculifer (Brady) under varying laboratory conditions, Mar. Micropaleontol., 12, 305-324, 1987.
Hemleben, C., Spindler, M., and Anderson, O. R.: Modern Planktonic Foraminifera, Springer-Verlag, New York, 1989.

Hillaire-Marcel, C., de Vernal A., Polyak, L., and Darby, D.: Sizedependent isotopic composition of planktic foraminifers from Chukchi Sea vs. NW Atlantic sediments-implications for the Holocene paleoceanography of the western Arctic, Quarternary Sci. Revi., 23, 245-260, 2004

Hodell, D. A. and Curtis, J. H.: Oxygen and carbon isotopes of detrital carbonate in North Atlantic Heinrich Events, Mar. Geol., 256, 30-35, 2008.

Ishimura, T., Tsunogai, U., and Nakagawa, F.: Grain-scale heterogeneities in the stable carbon and oxygen isotopic compositions of the international standard calcite materials (NBS 19, NBS 18, IAEA-CO-1, and IAEA-CO-8), Rapid Commun. Mass Sp., 22, 1925-1932, 2008.

Kahn, M. I.: Non-equilibrium oxygen and carbon isotopic fractionation in tests of living planktonic-foraminifera, Oceanol., 2, 195208, 1979.

Kennett, J. P.: Latitudinal variation in Globigerina pachyderma (Ehrenberg) in surface sediments of the southwest Pacific Ocean, Micropaleontology, 14, 305-318, 1968.

Killingley, J. S., Johnson, R. F., and Berger, W. H.: Oxygen and carbon isotopes of individual shells of planktonic foraminifera from Ontong-Java plateau, equatorial pacific, Palaeogeogr. Palaeoclimatol. Palaeoecol. 33, 193-204, 1981.

Kozdon, R., Ushikubo, T., Kita, N. T., Spicuzza, M., and Valley, J. W.: Intratest oxygen isotope variability in the planktonic foraminifer $N$. pachyderma: Real vs. apparent vital effects by ion microprobe, Chem. Geol., 258, 327-337, 2009.

Kroon, D. and Darling, K.: Size and upwelling control of the stable isotope composition of Neogloboquadrina dutertrei (D’Orbigny), Globigerinoides ruber (D’Orbigny) and Globigerina bulloides D'Orbigny: Examples from the Panama Basin and Arabian Sea, J. Foramin. Res., 25, 39-52, 1995.

Lohmann, G. P.: Increasing seasonal upwelling in the subtropical South Atlantic over the past 700000 yrs: Evidence from deepliving planktonic foraminifera, Mar. Micropaleontol., 19, 1-12, 1992.

Lohmann, G. P.: A Model for Variation in the Chemistry of Planktonic Foraminifera Due to Secondary Calcification and Selective Dissolution, Paleoceanography, 10, 445-457, 1995.

Lohmann, G. P. and Schweitzer, P. N.: Globorotalia truncatulinoides Growth and chemistry as probes of the past thermocline: 1. Shell size, Paleoceanography, 5, 55-75, 1990.

Lončarić, N., Peeters, F. J. C., Kroon, D., and Brummer, G.-J. A.: Oxygen isotope ecology of recent planktic foraminifera at the central Walvis Ridge (SE Atlantic), Paleoceanography, 21, PA3009, doi:10.1029/2005PA001207, 2006.

Lototskaya, A. and Ganssen, G. M.: The structure of Termination II (penultimate deglaciation and Eemian) in the North Atlantic, Quaternary Sci. Rev., 18, 1641-1654, 1999.

Lototskaya, A., Ziveri, P., Ganssen, G. M., and van Hinte, J. E.: Calcareous nannofloral response to Termination II at $45^{\circ} \mathrm{N}, 25^{\circ} \mathrm{W}$ (northeast Atlantic), Mar. Micropaleontol., 34, 47-70, 1998.

Löwemark, L., Konstantinou, K. I., and Steinke, S.: Bias in foraminiferal multispecies reconstructions of paleohydrographic conditions caused by foraminiferal abundance variations and bioturbational mixing: A model approach, Mar. Geol., 256, 101106, 2008. 
Macdonald, R. W., Paton, D. W., Carmack, E. C., and Omstedt, A.: The freshwater budget and under-ice spreading of Mackenzie River water in the Canadian Beaufort Sea based on salinity and ${ }^{18} \mathrm{O} /{ }^{16} \mathrm{O}$ measurements in water and ice, J. Geophys. Res.Oceans (1978-2012), 100, 895-919, 1995.

Malmgren, B. and Kennett, J. P.: Biometric analysis of phenotypic variation in Recent Globigerina bulloides d'Orbigny in the southern Indian Ocean, Mar. Micropaleontol., 1, 3-25, 1976.

McConnaughey, T. and McRoy, C. P.: ${ }^{13} \mathrm{C}$ label identifies eelgrass (Zostera marina) carbon in an Alaskan estuarine food web, Mar. Biol., 53, 263-269, 1979a.

McConnaughey, T. and McRoy, C. P.: Food-web structure and the fractionation of carbon isotopes in the Bering Sea, Mar. Biol., 53, 257-262, 1979b.

McIntyre, A., Kipp, N. G., Bé, A. W. H., Crowley, T., Kellogg, T., Gardner, J. V., Prell, W. L., and Ruddiman, W. F.: Glacial North Atlantic 18000 years ago: A CLIMAP reconstruction, Geol. Soc. Am. Memoirs, 145, 43-76, 1976.

McKenna, V. S. and Prell, W. L.: Calibration of the $\mathrm{Mg} / \mathrm{Ca}$ of Globorotalia truncatulinoides (R) for the reconstruction of marine temperature gradients, Paleoceanography, 19, PA2006, doi:10.1029/2000PA000604, 2004.

Mortyn, P. G. and Charles, C. D.: Planktonic foraminiferal depth habitat and ${ }^{18} \mathrm{O}$ calibrations: Plankton tow results from the Atlantic Sector of the Southern Ocean, Paleoceanography, 18, 1037, doi:10.1029/2001PA000637, 2003.

Mulitza, S., Dürkoop, A., Hale, W., Wefer, G., and Stefan Niebler, H.: Planktonic foraminifera as recorders of past surface-water stratification, Geology, 25, 335-338, 1997.

Oppo, D. W. and Fairbanks, R. G.: Carbon isotope composition of tropical surface water during the past 22000 years, Paleoceanography, 4, 333-351, 1989.

Ortiz, J. D., Mix, A. C., Rugh, W., Watkins, J. M., and Collier, R. W.: Deep-dwelling planktonic foraminifera of the northeastern Pacific Ocean reveal environmental control of oxygen and carbon isotopic disequilibria, Geochim. Cosmochim. Acta, 60, 4509-4523, 1996.

Ottens, J.: Planktic foraminifera as indicators of ocean environments in the Northeast Atlantic, PhD Academisch Proefschrift, Department of Sedimentary Geology, VU University Amsterdam, Amsterdam, 189 pp., 1992.

Park, M.-H.: Abrupt climatic changes induced by ice-rafting events in the eastern North Atlantic during the late Quarternary: stable isotope and X-ray mineralogical analyses, Geosci. J., 2, 59-67, 1998.

Peeters, F. J. C., Ivanova, E., Conan, S. M. H., Brummer, G.-J. A., Ganssen, G. M., Troelstra, S., and van Hinte, J.: A size analysis of planktic foraminifera from the Arabian Sea, Mar. Micropaleontol., 36, 31-63, 1999.

Peeters, F. J. C., Brummer, G.-J. A., and Ganssen, G. M.: The effect of upwelling on the distribution and stable isotope composition of Globigerina bulloides and Globigerinoides ruber planktic foraminifera) in modern surface waters of the NW Arabian Sea, Glob. Planet. Change, 34, 269-291, 2002.

Phleger, F. B., Parker, F. L., and Peirson, J. F.: North Atlantic Foraminifera, Elanders Boktryckeri Aktiebolag, 1953.

Ravelo, A. C. and Fairbanks, R. G.: Oxygen isotopic composition of multiple species of planktonic foraminifera: recorders of the modern photic zone temperature gradient, Paleoceanography, 7 , 815-831, 1992.

Ravelo, A. C. and Fairbanks, R. G.: Carbon isotopic fractionation in multiple species of planktonic foraminifera from core-tops in the tropical Atlantic, J. Foramin. Res., 25, 53-74, 1995.

Rink, S., Kühl, M., Bijma, J., and Spero, H. J.: Microsensor studies of photosynthesis and respiration in the symbiotic foraminifer Orbulina universa, Mar. Biol., 131, 583-595, 1998.

Rohling, E. J. and Bigg, G. R.: Paleosalinity and $\delta^{18} \mathrm{O}$ : a critical assessment, J. Geophys. Res.-Oceans (1978-2012), 103, 13071318, 1998.

Rosenthal, Y., Lohmann, G. P., Lohmann, K. C., and Sherrell, R. M.: Incorporation and preservation of $\mathrm{Mg}$ in Globigerinoides sacculifer: implications for reconstructing the temperature and ${ }^{18} \mathrm{O} /{ }^{16} \mathrm{O}$ of seawater, Paleoceanography, 15, 135-145, 2000.

Roucoux, K. H., Tzedakis, P. C., De Abreu, L., and Shackleton, N. J.: Climate and vegetation changes 180000 to 345000 years ago recorded in a deep-sea core off Portugal, Earth Planet. Sci. Lett., 249, 307-325, 2006.

Ruddiman, W. F. and McIntyre, A.: Northeast Atlantic paleoclimatic changes over the past 600000 years, Geol. Soc. Am. Memoirs, 145, 111-146, 1976.

Ruddiman, W. F. and McIntyre, A.: The North Atlantic Ocean during the last deglaciation, Palaeogeography, Palaeoclimatology, Palaeoecology, 35, 145-214, 1981.

Ruddiman, W. F., Raymo, M., and McIntyre, A.: Matuyama $41000-$ year cycles: North Atlantic Ocean and northern hemisphere ice sheets, Earth Planet. Sci. Lett., 80, 117-129, 1986.

Salmon, K. H., Anand, P., Sexton, P. F., and Conte, M.: Upper ocean mixing controls the seasonality of planktonic foraminifer fluxes and associated strength of the carbonate pump in the oligotrophic North Atlantic, Biogeosciences, 12, 223-235, doi:10.5194/bg12-223-2015, 2015.

Sarkar, A., Ramesh, R., and Bhattacharya, S. K.: Effect of sample pretreatment and size fraction on the $\Delta^{18} \mathrm{O}$ and $\Delta^{13} \mathrm{C}$ values of foraminifera in Arabian Sea sediments, Terra Nova, 2, 488-493, 1990.

Schiebel, R. and Hemleben, C.: Modern planktic foraminifera, Paläontologische Zeitschrift, 79, 135-148, 2005.

Schmidt, D. N., Thierstein, H. R., Bollmann, J., and Schiebel, R.: Abiotic Forcing of Plankton Evolution in the Cenozoic, Science, 303, 207-210, 2004.

Schmidt, D. N., Lazarus, D., Young, J. R., and Kucera, M.: Biogeography and evolution of body size in marine plankton, EarthSci. Rev., 78, 239-266, 2006.

Schmidt, D. N., Elliott, T., and Kasemann, S. A.: The influences of growth rates on planktic foraminifers as proxies for palaeostudies a review, Geological Society, London, Special Publications, 303 , 73-85, 2008.

Shackleton, N. J.: The high-precision isotopic analysis of oxygen and carbon in carbon dioxide, J. Sci. Instrum., 42, 689-692, 1965.

Shackleton, N. J.: Attainment of isotopic equilibrium between ocean water and the benthonic foraminiferal genus Uvigerina: isotopic changes in the ocean during the last glacial, Cent. Nat. Rech. Sci. Colloq. Int., 219, 203-209, 1974.

Shackleton, N. J. and Opdyke, N. D.: Oxygen isotope and palaeomagnetic stratigraphy of Equatorial Pacific core V28-238: Oxy- 
gen isotope temperatures and ice volumes on a 105 year and 106 year scale, Quaternary Res., 3, 39-55, 1973.

Shackleton, N. J. and Vincent, E.: Oxygen and carbon isotope studies in recent foraminifera from the southwest Indian Ocean, Mar. Micropaleontol., 3, 1-13, 1978.

Spear, J. W., Poore, R. Z., and Quinn, T. M.: Globorotalia truncatulinoides (dextral) $\mathrm{Mg} / \mathrm{Ca}$ as a proxy for Gulf of Mexico winter mixed-layer temperature: Evidence from a sediment trap in the northern Gulf of Mexico, Mar. Micropaleontol., 80, 53-61, 2011.

Spero, H. J. and DeNiro, M. J.: The influence of symbiont photosynthesis on the $\delta^{18} \mathrm{O}$ and $\delta^{13} \mathrm{C}$ values of planktonic foraminiferal s hell calcite, Symbiosis, 4, 213-228, 1987.

Spero, H. J. and Lea, D. W.: Experimental determination of stable isotope variability in Globigerina bulloides: implications for paleoceanographic reconstructions, Mar. Micropaleontol., 28, 231246, 1996

Spero, H. J., Bijma, J., Lea, D. W., and Bemis, B. E.: Effect of seawater carbonate concentration on foraminiferal carbon and oxygen isotopes, Nature, 390, 497-500, 1997.

Stone, S. W.: Some ecologic data relating to pelagic foraminifera, Micropaleontology, 2, 361-370, 1956.

Strain, P. M. and Tan, F. C.: Seasonal evolution of oxygen isotopesalinity relationships in high-latitude surface waters, J. Geophys. Res.-Oceans (1978-2012), 98, 14589-14598, 1993.

Telford, R. J., Li, C., and Kucera, M.: Mismatch between the depth habitat of planktonic foraminifera and the calibration depth of SST transfer functions may bias reconstructions, Clim. Past, 9, 859-870, doi:10.5194/cp-9-859-2013, 2013.

Thiede, J.: Planktonische Foraminiferen in sedimenten vom iberomarokkanischen Kontinentalrand, Meteor Forschungsergebnisse C, 15-102, 1971.

Thiede, J.: Shell- and skeleton-producing plankton and nekton in the eastern North Atlantic Ocean, "Meteor" Forschungsergebnisse Herausgegeben von der Deutschen Forschungsgemeinschaft, C, 33-79, 1975.

Tolderlund, D. S. and Bé, A. W. H.: Seasonal distribution of planktonic foraminifera in the western North Atlantic, Micropaleontology, 17, 297-329, 1971 .

van Sebille, E., Scussolini, P., Durgadoo, J., Peeters, F. J. C., Biastoch, A., Weijer, W., Turney, C., Paris, C. B., and Zahn, R.: Ocean currents generate large footprints in marine palaeoclimate proxies, Nature Communications, 6, 2015.

Vergnaud Grazzini, C.: Non-equilibrium isotopic compositions of shells of planktonic foraminifera in the Mediteranean Sea, Palaeogeography, Palaeoclimatology, Palaeoecology, 20, 263276, 1976.

Vetter, L., Kozdon, R., Mora, C. L., Eggins, S. M., Valley, J. W., Hönisch, B., and Spero, H. J.: Micron-scale intrashell oxygen isotope variation in cultured planktic foraminifers, Geochim. Cosmochim. Acta, 107, 267-278, 2013.
Vincent, E. and Berger, W. H.: Planktonic foraminifera and their use in palaeoceanography, in: The Sea, edited by: Emiliani, C., Wiley-Interscience, New York, 1025-1119, 1981.

Volten, H., De Haan, J. F., Hovenier, J. W., Schreurs, R., Vassen, W., Dekker, A. G., Hoogenboom, H. J., Charlton, F., and Wouts, R.: Laboratory measurements of angular distributions of light scattered by phytoplankton and silt, Limnol. Oceanogr., 43, 11801197, 1998.

Waelbroeck, C., Mulitza, S., Spero, H. J., Dokken, T., Kiefer, T., and Cortijo, E.: A global compilation of late Holocene planktonic foraminiferal ${ }^{18} \mathrm{O}$ : relationship between surface water temperature and ${ }^{18} \mathrm{O}$, Quaternary Sci. Rev., 24, 853-868, 2005.

Weiner, S.: The carbon isotopic composition of the eastern Mediterranean planktonic foraminifera Orbulina universa and the phenotypes of Globigerinoides ruber, Palaeogeogr. Palaeoclimatol. Palaeoecol., 17, 149-156, 1975.

Weinkauf, M. F. G., Moller, T., Koch, M. C., and Kučera, M.: Calcification intensity in planktonic Foraminifera reflects ambient conditions irrespective of environmental stress, Biogeosciences, 10, 6639-6655, doi:10.5194/bg-10-6639-2013, 2013.

Wefer, G., Berger, W. H., Bickert, T., Donner, B., Fischer, G., von Mücke, S. K., Meinecke, G., Müller, P. J., Mulitza, S., and Niebler, H.-S.: Late Quaternary surface circulation of the South Atlantic: The stable isotope record and implications for heat transport and productivity, in: The South Atlantic, Springer, 461502, 1996.

Weyl, P. K.: Micropaleontology and Ocean Surface Climate, Science, 202, 475-481, 1978.

Wilke, I., Bickert, T., and Peeters, F. J. C.: The influence of seawater carbonate ion concentration $\left[\mathrm{CO}_{3}^{2-}\right]$ on the stable carbon isotope composition of the planktic foraminifera species Globorotalia inflata, Mar. Micropaleontol., 58, 243-258, 2006.

Williams, D. F., Bé, A. W. H., and Fairbanks, R. G.: Seasonal oxygen isotopic variations in living planktonic foraminifera off Bermuda, Science, 206, 447-449, 1979.

Williams, D. F., Bé, A. W. H., and Fairbanks, R.: Seasonal stable isotopic variations in living planktonic foraminifera from Bermuda plankton tows, Palaeogeogr. Palaeoclimatol. Palaeoecol., 33, 71-102, 1981.

Williams, D. F., Ehrlich, R., Spero, H. J., Healy-Williams, N., and Gray, A. C.: Shape and isotopic differences between conspecific foraminiferal morphotypes and resolution of paleoceanographic events, Palaeogeogr. Palaeoclimatol., Palaeoecol., 64, 153-162, 1988.

Wit, J. C., Reichart, G. J., and Ganssen, G. M.: Unmixing of stable isotope signals using single specimen $\delta^{18} \mathrm{O}$ analyses, Geochem. Geophys. Geosys., 14, doi:10.1002/ggge.20101, 2013.

Wolfteich, C. M.: Satellite-derived sea surface temperature, mesoscale variability, and foraminiferal production in the North Atlantic, M.Sc., Massachusetts Institute of Technology/Woodshole Oceanographic Institution, 80 pp., 1994. 